\title{
The Dynamics of Personality Approach (DPA): 20 Tenets for Uncovering the Causal Mechanisms of Personality
}

\author{
MARKUS QUIRIN ${ }^{1,2 *}$, MICHAEL D. ROBINSON ${ }^{3}$, JOHN F. RAUTHMANN ${ }^{4}$, JULIUS KUHL ${ }^{5}$, STEPHEN J. READ ${ }^{6}$ \\ , MATTIE TOPS ${ }^{7}$ and COLIN G. DEYOUNG ${ }^{8}$ \\ ${ }^{1}$ Technical University of Munich, Munich, Germany \\ ${ }^{2}$ PFH Göttingen, Göttingen, Germany \\ ${ }^{3}$ North Dakota State University, Fargo, ND USA \\ ${ }^{4}$ Bielefeld University, Bielefeld, Germany \\ ${ }^{5}$ Osnabrück University, Osnabrück, Germany \\ ${ }^{6}$ University of Southern California, Los Angeles, CA USA \\ ${ }^{7}$ Leiden University, Leiden, The Netherlands \\ ${ }^{8}$ University of Minnesota, Minneapolis, MN USA
}

\begin{abstract}
Over the last few decades, most personality psychology research has been focused on assessing personality via scores on a few broad traits and investigating how these scores predict various behaviours and outcomes. This approach does not seek to explain the causal mechanisms underlying human personality and thus falls short of explaining the proximal sources of traits as well as the variation of individuals' behaviour over time and across situations. On the basis of the commonalities shared by influential process-oriented personality theories and models, we describe a general dynamics of personality approach (DPA). The DPA relies heavily on theoretical principles applicable to complex adaptive systems that self-regulate via feedback mechanisms, and it parses the sources of personality in terms of various psychological functions relevant in different phases of self-regulation. Thus, we consider personality to be rooted in individual differences in various cognitive, emotional-motivational, and volitional functions, as well as their causal interactions. In this article, we lay out 20 tenets for the DPA that may serve as a guideline for integrative research in personality science. (C) 2020 The Authors. European Journal of Personality published by John Wiley \& Sons Ltd on behalf of European Association of Personality Psychology
\end{abstract}

Key words: dynamics of personality approach (DPA); systems theory; cybernetics; within-person variability; personality structure; personality processes; personality functions; cybernetic big five theory; personality systems interactions theory; virtual personalities model; computational modelling; personality neuroscience / predictive and reactive control systems theory

What kind of theoretical framework is most adequate to comprehensively understand and explain human personality? This question has not lost its relevance from the origins of personality psychology as an academic discipline up to the present day (Corr, 2020). Over the last half century, personality psychology has been predominantly focused on developing consensual descriptions of personality, largely on the basis of taxonomies created by factor analysis, and using those descriptive models to investigate what outcomes are predicted by trait measures as well as how those scores change over time. In the last decade, however, personality researchers have become increasingly interested in investigating the causal mechanisms and processes underlying

\footnotetext{
*Correspondence to: Markus Quirin, Department of Psychology, School of Management, Technical University of Munich, Arcisstraße 21, $80333 \mathrm{Mu}-$ nich, Germany.

E-mail: m.quirin@tum.de

Paper draft submitted to a Special Issue of the European Journal of Personality: New approaches toward conceptualizing and assessing personality, René Mõttus, David Condon, Dustin Wood, Sacha Epskamp (Eds.)
}

personality functioning (e.g. Baumert et al., 2017; DeYoung, 2015; Mõttus, Condon, Wood, \& Epskamp, 2018; Rauthmann, 2015, 2020; Robinson, Klein, \& Persich, 2019; Shoda, Wilson, Chen, Gilmore, \& Smith, 2013; Wood, Gardner, \& Harms, 2015), reviving an earlier phase of theoretical development (e.g. Atkinson \& Birch, 1970; Block, 1995; Cervone \& Shoda, 1999; Kuhl, 1994; Kuhl \& Atkinson, 1986; Mischel \& Shoda, 1995; Vallacher, Read, \& Nowak, 2002). Such research is focused on resolving major questions about the sources of variation in personality and about how individuals' behaviours and experiences vary from situation to situation despite the fact that personality traits are themselves relatively stable (DeYoung \& Weisberg, 2018).

A number of process-oriented models and theories of personality have been developed during the last two decades (e.g. Collins, Jackson, Walker, O'connor, \& Gardiner, 2017; Fajkowska, 2015; Mayer, 2015; Revelle \& Condon, 2015; Sosnowska, Kuppens, De Fruyt, \& Hofmans, 2019; Van Egeren, 2009), which demonstrates the increasing interest 
in uncovering the mechanisms underlying personality. Some models have also been developed by authors of the present work (DeYoung, 2015; Kuhl, 2000a,b; Kuhl, Quirin, \& Koole, 2020; Tops, IJzerman, \& Quirin, 2020; Quirin, Tops, \& Kuhl, 2019; Read et al., 2010; Read, Droutman, \& Miller, 2017; Tops, Boksem, Luu, \& Tucker, 2010; Tops, Montero-Marín, \& Quirin, 2016). These models and theories differ in important respects, but all endorse a systemstheoretical approach in one way or the other, referring to control theory, cybernetics, cognitive architectures based on neural networks, or other theories of complex dynamic and adaptive systems. Here, we refer to the common assumptions of these different approaches as the dynamics of personality approach (DPA). The DPA attempts to explain the structure and dynamics of human personality as a complex adaptive system that is able to regulate its own behaviour and experience via feedback processes (e.g. Carver \& Scheier, 1998; Powers, 1973).

We intend to highlight the importance of systemstheoretical thinking for personality psychologists and, throughout this article, formulate specific tenets for a solid DPA that can serve to tie different dynamic approaches together, which could be instrumental for future research on personality and its underlying mechanisms (Table 1). Beyond that, we believe that the DPA constitutes a meaningful, cross-disciplinary framework for conceptualizing phenomena (e.g. person-situation interactions, psychopathology) at the intersection of personality psychology and neighbouring disciplines, thus furthering the integration of personality psychology with social, motivational, clinical psychology, and beyond. Our goal here is not to present a single definite theory of personality but rather to present the important components of an approach to the development of any such theory.

We start by reviewing general systems-theoretical principles and types of mechanisms that are necessary for a basic understanding of the DPA. Next, we delineate psychological functions (i.e. cognitive, affective-motivational, and volitional) as central elements in the DPA that correspond to individual difference variables and postulate that any DPA model should explicate how these functions causally interact with each other within the individual. By using some examples, we will also demonstrate how these functions might be linked to commonly studied personality traits. Subsequently, we will argue that these psychological functions evolved to optimize efficient goal pursuit and thus play specific roles in different phases of self-regulation. After highlighting that

Table 1. Tenets for the DPA

Tenet 1 The DPA aims to understand the proximal causes of personality-related phenomena.

Tenet 2 Feedback loops are a defining mechanism of the DPA; individuals adapt their functioning on the basis of the results of their behaviour.

Tenet 3 Goals, understood broadly as desired states, can be conscious or unconscious, as can be the mechanisms applied to achieve goals.

Tenet 4 The DPA addresses within-person variables that fluctuate dynamically in response to changing goals and changing situations. We refer to these within-person variables as psychological functions.

Tenet 5 DPA models must specify how stable between-person differences emerge from the interactions of psychological functions and are generated by between-person variation in some relatively stable parameters of the dynamic mechanisms that govern within-person self-regulation.

Tenet 6 Psychological functions comprise cognitive (basic vs. higher level), emotional-motivational, and volitional variables.

Tenet 7 Important individual differences exist in the readiness with which individuals engage in and maintain specific psychological functions.

Tenet 8 DPA models should address interactions among these psychological functions and individual differences in them.

Tenet 9 Explaining how, when, and why psychological functions relate to each other to produce a common trait is a central issue for the DPA.

Tenet Objective or indirect measures are necessary in assessing the mechanisms underlying personality functioning, to avoid confusing the

10 phenomena to be explained (behaviour and experience) with the explanatory mechanisms.

Tenet It is heuristically useful to describe self-regulation in terms of a sequence of phases or stages.

11

Tenet Switching between phases of self-regulation can be facilitated by volition, such as the flexible upregulation and downregulation of 12 emotions and other functions.

Tenet Emotional-motivational, cognitive, and volitional functions can be considered to have evolved to serve a particular purpose in 13 self-regulation and thus to be of differing importance in different self-regulation phases.

Tenet All humans share an evolutionarily developed, nomothetic structure of functional variables and operations, and the functional 14 requirements of that structure are in part summarized by a set of self-regulation phases.

Tenet Individual differences largely stem from differing tendencies in how readily individuals enter and exit specific self-regulation phases 15 or from the degree to which they apply certain functions within these phases.

Tenet The DPA encompasses a personality-by-situations view by considering moment-to-moment transactions of individuals with 16 situations.

Tenet To investigate person-environment transactions systematically, it is indispensable to understand and describe the characteristics of 17 situations as they constitute affordances for affective, motivational, cognitive, or volitional functions within individuals.

Tenet Neuroscientific insights are helpful for advancing our understanding of the causal structure of human personality.

18

Tenet The same kind of overt behaviour may stem from different underlying functions on different occasions.

19

Tenet Computational modelling constitutes a prime method for deciphering the causal network of mechanisms underlying personality and 20 the variability of behaviour.

Note: DPA, dynamics of personality approach. 
the investigation of temporal dynamics of person-bysituation interactions is key to the DPA, we discuss its compatibility with neuroscientific research and models (e.g. predictive coding). Not least, we advocate computational modelling as a prime method in the DPA, which can be used to investigate the causal mechanisms of personality. Throughout the paper, we mention tenets, 20 in total, that we deem central for the DPA and related research (also Table 1). By doing so, we demonstrate how the DPA has the potential to integrate approaches investigating variations between individuals as well as approaches investigating variations within a person over time.

\section{THE DPA: A SYSTEMS-THEORETICAL ACCOUNT OF PERSONALITY PROCESSES AND STRUCTURE}

The DPA uses systems (or 'control' or 'cybernetic') theory (Carver \& Scheier, 1998; Powers, 1973; Wiener, 1948) as a general framework to conceptualize, analyse, and (eventually) computationally simulate personality and its functioning. Although systems theory has an extremely broad scope, here, we are referring to it as it applies to complex adaptive systems. In this context, systems theory describes and explicates general principles of complex systems, human beings included, that self-regulate their behaviour across time and situations, through feedback processes. It constitutes a general explanatory framework that provides principles to organize the understanding of causal relationships between variables involved in complex adaptive systems. Therefore, it largely abstracts from the materials (e.g. blood vessels, neural networks, or computer circuit boards) that serve as a basis for the causal transference of information within a system. Indeed, systems-theoretical principles are independent of the system at hand, be it an ecosystem, a societal system, a group of interacting agents, a plant or animal's body, a robot, or the human psyche. Hence, systems theory can be applied in personality research to analyse the network of causal mechanisms underlying personality functioning, or even to implement it in a computer program or a robot to simulate a human's personality and behaviour.

One of the major challenges for explanatory theories in personality psychology is to explain how personality traits can be stable and persistent while behaviour changes from moment to moment in response to both situational cues and fluctuations in processes within the person (e.g. changes in the strength of motives). Part of the appeal of systems theory is that it provides tools for explaining the relative stability of systems despite their constant interaction with their environments. This particularly applies to systems of so-called operational (or operative, autopoetic) closure (e.g. Luhmann, 1992), which typically have definable borders that distinguish them from their environment, such as the boundaries of the human body, and which maintain a network of variables that are causally connected to each other via congeneric operations. These systems interact with their environments by taking in information (input) that triggers internal operations and by producing outcomes (behavioural output) that causally influence the environment (Rauthmann, 2016).
Thus, there is a constant state of dynamic interplay and change between the system and its environment.

By adopting this systems-theoretical orientation, the DPA differs from descriptive, trait approaches to personality, which typically focus on what is stable in the person and use that to predict other individual differences in traits, outcomes, and so forth. Descriptive approaches typically attempt to provide an economical taxonomy of personality dimensions (or types) deriving from the covariation of behaviour and experience observed between individuals, most often identified by factor analyses of questionnaire ratings. The DPA is not opposed to the descriptive approach and, in fact, can be complementary to it, attempting to identify causal mechanisms that lead to the patterns of covariation identified by descriptive taxonomies. Neither are typical descriptive approaches necessary for the DPA, however, as researchers may focus mainly on individual difference parameters that are prominent or particularly meaningful in their theoretical account.

Systems theory can also be integrated with ideas about evolutionary function to address questions about why variables evolved to relate to each other in a certain way (e.g. Lukaszewski, 2013). This can be fruitful in the DPA because evolutionary considerations (e.g. of adaptation and fitness) can be used to generate hypotheses about a proximate causal network of variables or to integrate the hypothesized account of mechanism within a broader socio-biological context by adding the question of the distal 'why' to the question of the proximal 'how'. Despite this potentially helpful add-on of evolutionary perspectives, the core of the DPA, as we see it, is primarily to disentangle proximal rather than distal causes of personality-related phenomena (Tenet 1, Table 1).

In systems theory applied to proximal causes, the causal network of variables can be analysed structurally ('conceptually') or quantitatively ('mathematically') (Bischof, 2016). Structural systems analysis posits questions about the causal structure of variables in the form of 'Does X cause $Y$ ?', 'Does $Y$ cause $X$ ?', or 'Do $X$ and $Y$ engage in mutual causation?' as well as questions about the extent to which such causal relationships have facilitatory or inhibitory relationships. When three or more variables are under consideration, the topological structure of their causal relationships can assume more complex forms, such as a chain, a mesh, a fork (bifurcation), or the well-known feedback loop. These forms can be depicted as so-called signal flow graphs (Mason, 1953) - the bedrock of virtually all graphical depictions of causal relationships (e.g. Pearl, 2009; Spirtes, Glymour, \& Scheines, 2000). A signal flow graph consists of a network of directed branches that connect at nodes and which have been used in theories of human personality as well (e.g. Lee, 2012). Accordingly, in the DPA, the structure of personality refers to the nomothetic network of causal relationships among within-person variables (psychological functions; refer to succeeding discussion) rather than to the between-person covariance pattern of traits.

Structural systems analysis can be considered a prerequisite for quantitative systems analysis, which attempts to determine mathematically describable relationships between variables in a network (Bischof, 2016; Powers, 1978). For 
example, motivation researchers may ask whether the relationship between strength of incentive-driven approach motivation and the distance from the incentive is linear or non-linear (e.g. logarithmic), how strong its slope is (Miller, 1944), or how within-system (person) variables causally relate to each other during so-called transition states (instability between two stable, balanced states), as typically described by differential equations (Bischof, 2016). Quantitative systems analysis, as typically realized by computational modelling (refer to succeeding section), thus allows for predictions of a system's complex dynamic behaviour and puts the hypothesized causal network of variables to the test.

\section{SELF-REGULATION VIA NEGATIVE FEEDBACK CONTROL: AN ELEMENTARY DPA PRINCIPLE}

In self-regulation, the system controls a variable or set of variables physically instantiated within itself. Feedback loops are a defining mechanism of the DPA because an adaptive system autonomously attempts to adjust a current state to a target state, thereby pursuing goals, which requires feedback concerning its states (Tenet 2) (e.g. Carver \& Scheier, 1998; Powers, 1973). In the simplest case of a loop involving two variables, a variable A causally influences a variable B, which in turn causally influences A. If this happens in a way that the value of A remains relatively stable or 'in balance', the causal structure is called a homeostatic loop, with $\mathrm{B}$ exerting negative feedback control over A (as compared with a positive feedback loop that leads to an increasing divergence of the variables' values: Carver \& Scheier, 1998). Homeostatic processes are common in organisms-for example, to maintain variables like temperature within ranges conducive to life. However, not all negative feedback processes are homeostatic, as some reduce the distance between the system's current state and a goal state that has not previously been achieved (e.g. obtaining a promotion within one's company, or becoming better at regulating one's emotions). Negative feedback control, then, is involved whenever one seeks to change a current state to a desired state. In negative feedback, the system attempts to reduce the discrepancy between these states, and detection of that discrepancy constitutes error. For example, humans may strive for food, security, autonomy, and arousal to meet a particular person, to win a game, or to simply relax, all to some desired degree. The system's representation of the desired state or outcome, the value or value range toward which negative feedback leads, is what can be described as a goal in cybernetic theory.

In the cybernetic or control theory tradition, the term 'goal' is typically used to designate any desired outcome state that the system is striving for (DeYoung \& Weisberg, 2018). This contrasts with the manner in which goals are typically thought of in psychology, where distinctions are often made between goals, intentions, motives, and needs. Within the latter tradition, goals may signify the conscious representation of a desired outcome state such as passing an exam (Elliot \& Fryer, 2008), and intentions may signify prospective actions to obtain the desired outcome
(Cottini \& Meier, 2020; Goschke \& Kuhl, 1993). Not least, the concept of motive, instead of focusing on one specific entity such as a desired outcome or a prospective action, denotes an associative network of possible actions, outcomes, and goals that satisfy or frustrate a particular need (McClelland, 1985).

Compared with goals, needs can be conceived of in terms of desired outcomes that are evolved components of human nature and rooted in deeper organismic states. For example, the goal to make friends with somebody may be rooted in the deep organismic need for affiliation (relatedness), which in turn may be integrated in an associative motive network of relevant incentives, actions, and outcomes (Deci \& Ryan, 2011; Kuhl et al., 2020; McClelland, 1985). Notably, goals, intentions, needs, and motives are interconnected and can shift over time, both phasically and tonically, which renders complex systems like humans capable of extensive adaptation. For example, a particular goal or motive (e.g. the motive for affiliation) may be aroused (disinhibited) in the presence of a key affording incentive or situation, as when appetite emerges with the occurrence of food or with the onset of eating. This corresponds to a phasic change in the goal from pre-stimulus to post-stimulus exposure, and the amount of change in that goal can be characterized in terms of individual differences in a motive or its activation potential (McClelland, 1985). Likewise, internal developmental and learning processes may shift a goal tonically or even permanently. It is worth pointing out that the DPA perspective extends the idea of goals to unconscious as well as conscious control processes, so long as the system employs some sort of feedback control to reach a desired state (Tenet 3 ).

At a minimum, a cybernetic control system requires a representation of the goal state of the controlled variable (in complex systems like organisms, this desired target state can change over time), a sensor of the current state of that system that allows comparison between the two (or 'error detection') via feedback, and a set of operators that actively adjusts the system's behaviour in such a way as to move the current state toward the goal state. Most organisms, and certainly human beings, incorporate other more complicated modes of self-regulation, including positive feedback (in which discrepancies are increased instead of reduced) and feedforward (in which predictions about the future state are used to control action). In systems capable of self-regulation, however, these other types of control are bounded by negative feedback processes, which provide a standard to strive for to keep the system within its adaptive range.

Typically, individuals pursue multiple goals (including intentions, motives, and needs) over a given period of time, with only one or two being active in working memory at any given time. Quiescent goals can become reactivated at any time, however. This occurs when actively remembering goals that one is not currently pursuing or upon passive exposure to cues relevant to a goal, especially when those cues suggest that a goal may be thwarted. Such processes frequently lead to the occurrence of several feedback control processes overlapping within a particular stretch of time (Carver \& Scheier, 1998). In fact, the possibility that activation of motivational states can vary over time and situations 
is a defining feature of organismic systems as compared with many technological systems, which continually work on preset goals, as in the earliest cybernetic models (Wiener, 1948). Among humans, motivational states can even become chronically deactivated when an individual has not worked on them for a long time or when the pursuit of related goals has been problematic in the past (Brandstätter \& Herrmann, 2018; Rasmussen, Wrosch, Scheier, \& Carver, 2006).

\section{PSYCHOLOGICAL FUNCTIONS AS THE BASIC PERSONALITY COMPONENTS IN THE DPA}

Personality trait variables - as favoured by descriptive, factor-analytical approaches - refer to between-person variables, conceived as changing only very slowly or slightly within a person under normal circumstances (Specht et al., 2014). The DPA, in contrast, is primarily (yet not exclusively) focused on within-person variables that fluctuate dynamically in response to changing goals and changing situations. We refer to these distinct within-person (or 'process') variables as psychological functions (Tenet 4). Rather than using the term 'function' in an evolutionary sense, it is used here to refer to the manner in which a process contributes to the goal-directed functioning of the system (DeYoung \& Krueger, 2018). Cognitive functions, for example, refer to sensorimotor control, analytical thinking, memory, attention, holistic thought, and so on-universal human processes that can be more or less activated or inhibited at any given moment.

Despite focusing on psychological functions, any comprehensive DPA must address stable individual differences in addition to internal dynamic processes, or it would not be an approach to personality. Thus, DPA models must specify how stable individual differences emerge from the interactions of within-person functions and are generated by between-person variation in some relatively stable parameters of the dynamic mechanisms that govern within-person self-regulation (Tenet 5). Descriptive traits often encompass various variables (e.g. the Big Five domains, aspects, or facets) that may correlate on a population level but may be caused not by one single underlying causal function (e.g. Wood et al., 2015), but by the operation of multiple psychological functions and their causal interplay (e.g. several distinct cognitive and motivational processes are likely to contribute to openness to experience: DeYoung, 2015). Additionally, it is possible that different functional interactions may produce the same level of a behavioural trait in different people.

Personality traits are often defined as relatively stable patterns of emotion, motivation, cognition, and behaviour (e.g. DeYoung, 2015; McAdams \& Pals, 2006; Wilt \& Revelle, 2009). Here, however, we would like to bring a slightly different perspective to bear, that is, to explain personality in terms of the pattern of cognitive, emotionalmotivational, and volitional functions, but not behaviour in itself (Tenet 6). This approach has at least two important implications. First, we discuss volition as a distinct category of psychological functions in order to highlight the fact that particular functions may be voluntarily engaged or disengaged at any particular moment of time, thus stressing the notion of top-down control in the study of individual differences.

Second, because observable behaviour is not an explanatory psychological function but rather an output or outcome, we will not discuss behaviour itself as a psychological function in any narrow sense. Making such distinctions allows the DPA to meaningfully explore relationships between function-level constructs (e.g. emotion/motivation, cognition, and volition), how they are activated by stimuli and situations, and how they determine behavioural responses (Fajkowska, 2015; Smillie, 2013). Our suggestion to separate psychological functions from behaviour is also driven by the fact that outwardly similar behaviours can be caused by different underlying psychological functions, and the same psychological functions may lead to different behaviours (Funder, 1991). For example, an individual may approach strangers (typically conceived of as an extraverted behaviour) in order to reduce one's anxiety, to ask for help, or out of boredom (Berlyne, 1960). Behaviour may nevertheless point to operations or psychological functions if accurately observed over time and in a variety of appropriate situations.

Behaviour and experience ultimately result from the complex interplay of psychological functions, the activation levels of which can fluctuate from moment to moment as a reaction to internal (e.g. goals and motives) and external (situational) cues. Although all functions we consider here are present in each individual, they are nevertheless subject to individual differences in their operation. These differences largely refer to the readiness with which individuals engage in and maintain specific psychological functions (Tenet 7; e.g. in analytical thinking as a cognitive function, or affiliation as a motivational function). In what follows, we provide an overview of these classes of psychological functions and discuss relevant individual differences for each one (Table 2). Models developed through the DPA (at least those aiming to be integrative or comprehensive) should address causal interactions among these functions and individual differences in them (Tenet 8).

\section{Emotion and motivation}

Motivations are inclinations of the system to move toward particular goal states. Emotion and motivation are difficult to separate, as emotions typically have a motivational component (i.e. they incline people toward particular actions or types of action, or disrupt an action: Frijda, 2016), and motivations typically have emotional components. Although human beings experience a wide range of emotions, any DPA model will need to deal at least with the basic emotionalmotivational categories of reward and punishment. From the perspective of the DPA, rewards are associated with positive emotions and indicate movement toward or accomplishment of goals. By contrast, punishments are associated with negative emotions and signify threats or other aversive events (e.g. failure to accomplish one's goals).

Two kinds of rewards should be distinguished, which relate to two different motivational phases. Specifically, 
Table 2. DPA taxonomy of psychological functions

\begin{tabular}{ll}
\hline Process level & \multicolumn{1}{c}{ Examples } \\
\hline Volition & Emotion regulation, self-control, self-regulation \\
High-level cognition & Analytical-sequential and holistic-contextual thought \\
Motivation and emotion & Incentive and hedonic reward, threat and defeat punishment \\
Low-level cognition & Sensorimotor control, error detection \\
\hline
\end{tabular}

Note: DPA, dynamics of personality approach.

whereas incentive rewards indicate progress toward a goal, hedonic (or 'consummatory') rewards signal that the goal has been achieved. Incentive rewards, which gain their power through mesolimbic dopamine circuits (Berridge, 2007), induce feelings of desire (or 'wanting'), which trigger effort and associated emotions like excitement. By contrast, hedonic rewards induce feelings of enjoyment or relaxation resulting from goal attainment (e.g. liking of food, hugs, orgasm, or even completed work), which can be linked to functioning of the endogenous opiate system (Berridge, 2007). Accordingly, desire for incentives supports goal pursuit, whereas hedonic enjoyment serves as a signal that the pursued rewards were worth the effort, thus stimulating future goal pursuit of the same class of incentives. Incentive and hedonic rewards can refer to different stimuli/categories that activate or inhibit cognitive or volitional functions differentially. For example, social rewards and object-oriented rewards activate different motives (e.g. of affiliation, power, and achievement). As another example, a preponderance of object-related reward sensitivity in infants predicts impairment later in development, whereas early person-related reward sensitivity predicts subsequent facilitation of the development of self-regulatory skills (Kochanska, Aksan, Penney, \& Doobay, 2007).

Similar to rewards, we can distinguish between two kinds of punishments (e.g. DeYoung \& Weisberg, 2018). Specifically, threats are cues that indicate the possibility of a future goal thwarting, including aversive physical stimulation, and they typically evoke negative emotions such as fear, anxiety, and worry. By contrast, defeats reference the immediate experience of failure and other types of goal thwarting and typically give rise to negative emotions such as frustration, dejection, helplessness, and hopelessness. Threat is typically considered to elicit fear or anxiety, whereas defeat is typically considered to elicit frustration or depression. Relative to trait anxiety, trait depression shows a unique pattern of associations with other traits suggesting reduced motivation and lower dopaminergic activity (DeYoung, 2013). Anxiety is linked to increased error sensitivity, which can also be linked to threat rather than defeat (Higgins, 1997; Kuhl, 2000a; Kuhl et al., 2020). Anxiety is highly co-morbid with anxiety; however, once depression predominates over anxiety, individuals show decreased rather than increased error sensitivity (Weinberg, Kotov, \& Proudfit, 2015). This makes sense because ceasing to care about goals decreases their salience and therefore decreases the degree to which they can trigger error signals in relation to the present state.
The specific emotion that a person experiences when goals are achieved or thwarted is also likely to depend on the nature of the goal or motive involved (e.g. object-related or social; affiliation or power). For example, unsatisfied attachment needs can give rise to feelings of loneliness or existential anxiety, which may trigger proximity-seeking behaviours. By contrast, unsatisfied or thwarted power motivation can lead to feelings of oppression, which might motivate assertion. Hence, even though reward and punishment are basic event types, they can give rise to a wide diversity of experiences and corresponding behaviours, because people pursue a wide range of different motives and goals (McClelland, 1985).

\section{Individual differences in motivation and emotion}

Individual differences in motivation and emotion may be seen as core to a number of commonly studied personality traits (although not all commonly studied traits, as our analysis in the following sections will suggest). Among these is the Big Five trait of neuroticism, which is linked to all sorts of negative (threat-related and punishment-related) emotions. Indeed, the tendency toward negative emotions appears to constitute the core of this trait (Watson, 2000). Extraversion is not as purely focused on emotion as neuroticism is but nonetheless appears to encompass the tendency to experience many positive, reward-related emotions; and such emotions may be central to the trait (Watson, 2000). The reinforcement sensitivity theory tradition (Corr, 2004) seeks to assess traits related to behavioural approach sensitivity, behavioural inhibition sensitivity, and fight-flight-freeze sensitivity that describe emotional and motivational responses to rewarding and punishing stimuli. And many emotions are simply measured as traits in their own right by asking people about their typical levels of anxiety, anger, curiosity, shame, pride, and so forth.

\section{Cognition}

Some psychological functions are primarily cognitive in nature. These include basic functions related to attention and sensorimotor processes, which can be identified among all vertebrates, as well as higher-level functions that are more evolutionarily recent, such as analytical-propositional versus holistic-associative thinking (see Anderson, 1983, vs. Rumelhart, McClelland, \& PDP Research Group, 1986, for theoretical models of propositional vs. holistic processing).

One functional aspect of attention relevant for personality function is conscious error detection (error awareness). Error 
detection occurs when there is a discrepancy between performance and expectation, which initiates an orienting response, narrows attention toward the mismatch, and facilitates detailed, conscious processing. Narrowed, conscious attention is associated with analytical rather than holistic processing (Hsieh, Yu, Chen, Yang, \& Wang, 2020) and is facilitated by negative and positive (arousing) stimuli, albeit more strongly by negative ones (e.g. Easterbrook, 1959; Kazén, Kuhl, \& Quirin, 2015; Pool, Brosch, Delplanque, \& Sander, 2016). By contrast, a broad scope of attention, which is present in the absence of perceived errors or concrete expectations, facilitates the consideration of contextual variables as well as the interoception of emotional preferences and values (which has been referred to as self-access; e.g. Quirin \& Kuhl, 2018). At the same time, a broad scope of attention lowers the likelihood of consciously detecting discrepancies, details, embedded objects or task-irrelevant information (Davis \& Cochran, 2017; Hsieh et al., 2020). Broad attentional scope is often facilitated by positive affect (Fredrickson, 2001; Lindquist, Satpute, Wager, Weber, \& Barrett, 2015) and especially by positive emotions related to hedonic rewards (as incentive rewards narrow one's focus on the goal: Gable \& Harmon-Jones, 2008; Pool et al., 2016).

Another basic class of cognitive function is sensorimotor processing and coordination (Lehéricy et al., 2006; Takeshima \& Gyoba, 2014). Sensorimotor processing can operate without conscious attention or deliberation, for example, when stimulus-response patterns become automatically elicited as, for example, in non-verbal social interaction such as sensorimotor synchronization, emotional contagion, or intuitive parenting (Boccia, Piccardi, Di Marco, Pizzamiglio, \& Guariglia, 2016; Dumas, Nadel, Soussignan, Martinerie, \& Garnero, 2010; Keller, Chasiotis, \& Runde, 1992; Miller, Xia, \& Hastings, 2019). Sensorimotor coordination relies on peripheral ('preconscious') perception of stimulus or own-body locomotion, as supported by the dorsal visual stream (Ungerleider \& Mishkin, 1982), or the mirror-neuron system in the context of interpersonal coordination and imitation (Endedijk, Meyer, Bekkering, Cillessen, \& Hunnius, 2017). Sensorimotor processing can be relevant in the consideration of expertise or competence and may also play important roles in the manner in which practiced goals lead to practiced responses.

High-level cognitive functions, by contrast, allow individuals to create action scripts and models of the world, which can facilitate solving complex problems. Such models are useful in decision making because they allow the organism to anticipate likely future states, in part by anticipating the results of one's actions. Among human beings, such models can be holistic/associative, keeping track of what patterns of sensory inputs typically co-occur, or they can be analytical (i.e. causal, logical, and propositional), developing models of the rules that govern transitions between states and the range of conditions currently obtained based on those rules (e.g. Epstein, 2003; Kahneman, 2003; Lieberman, 2003; Strack $\&$ Deutsch, 2004). Sometimes, it can be useful to process information (conceptual thought or attention) in a slow, analytical way, which can help one avoid mistakes. At other times, it can be useful to process information in a holistic- associative way (e.g. to make a quick decision if necessary). Analytical processing is a cognitive function well suited for planning sequences of subgoals needed to reach an end goal. By contrast, holistic-associative processing facilitates experiential absorption in any activity, whether directed toward a concrete goal or not (Kuhl \& Kazén, 2008; Tellegen, 1981, 1982; Tellegen \& Atkinson, 1974).

\section{Individual differences in cognition}

Although we have described analytical versus holistic thinking as two general modes of information processing, such dual-process frameworks have most heuristic value when one recognizes the multiplicity of cognitive processes at both conscious and automatic levels. To encourage greater specificity as well as applicability to the personality realm, it may be important to develop more differentiated models that specify functions within each of the larger dual-process categories. For example, the personality trait intellect (which relates to analytical or reflective thinking: Kaufman et al., 2010; Strack \& Deutsch, 2004) entails some ambiguity from a personality functions standpoint because its manifestations can reflect both cognitive functions (e.g. efficiency or sensitivity of a cognitive subsystem) or motivational functions related to interest (e.g. DeYoung, 2015; Smillie, Varsavsky, Avery, \& Perry, 2016). Similarly, openness to experience refers to some processes that have a cognitive basis, such as in detecting new patterns in sensory and perceptual activity (e.g. with respect to art or music), but also has an emotional component involving hedonic enjoyment of those patterns. These examples highlight the fact that most traits involve multiple or different types of psychological function, although one may predominate (e.g. Pytlik Zillig, Hemenover, \& Dienstbier, 2002). Explaining how, when, and why such functions relate to each other to form a common trait can be considered a central issue for the DPA (Tenet 9).

The scope of one's associative processing, which has been analysed in experimental research (e.g. Kuhl, 2000a; Kuhl et al., 2020; Quirin, Düsing, \& Kuhl, 2013), can also be considered a cognitive function that is likely to contribute to personality tendencies related to openness, with highly open people having a larger scope of associative processing. There is also evidence that individuals differ in low-level cognitive functions. For example, extraversion has been related to faster sensorimotor processing as identified by electroencephalographic research (De Pascalis, Sommer, \& Scacchia, 2018; Stahl \& Rammsayer, 2008). Similarly, neuroticism could centrally involve sensitivities related to error detection (Olvet \& Hajcak, 2008).

\section{Volition}

In contrast to motivation, which implicates basic drives related to approach and avoidance (which are endemic to all living organisms: Schneirla, 1959), volition, sometimes described as 'self-control' (Baumeister, 2014), refers to the purposeful regulation of mental activities that will facilitate one's intended goals in the context of competing goals (e.g. distractions or temptations). Volition, as we describe it here, 
is distinct from our descriptions of cognition or motivation in that it involves superordinate control mechanisms that orchestrate elements of both cognition (e.g. knowledge representation and thinking) and motivation/emotion (Kuhl \& Fuhrmann, 1998).

Volition functions not only by counteracting immediate impulses and action tendencies that might compromise the pursuit of a current goal but also through processes that upregulate or downregulate emotions that could facilitate or interfere with one's efforts. In other words, volition includes elements of emotion regulation (Gross, 2014; Koole, 2009; Kuhl, 2000a). In a volitional process, one might quiet emotional states that would interfere with one's efforts (e.g. anxiety), while cultivating other emotions when those emotions would be advantageous (Shah, Friedman, \& Kruglanski, 2002; Tamir, 2016). Thus, volition may benefit from emotional intelligence, which includes capacities to create emotional experiences that are suited to the task at hand (Cohen \& Andrade, 2004; Salovey \& Grewal, 2005).

\section{Individual differences in volition}

Based on different theoretical or empirical (e.g. factoranalytical) approaches, a number of individual differences relevant to volition have been postulated. The Big Five factor conscientiousness reflects a general tendency toward being industrious, organized, self-disciplined, and orderly. Other volitional individual difference constructs include those described as 'regulatory focus', which can be either toward promotion, a mode of goal pursuit in which one strives to obtain rewards, or prevention, a mode of goal pursuit in which one strives to avoid negative outcomes, including defeats and failures to fulfil obligations (Higgins, 1997). One can also distinguish modes of volition that involve constraint and rigidity (e.g. self-discipline or self-control) versus context sensitivity and flexibility (Kuhl \& Fuhrmann, 1998). For example, in the latter mode, the person might pause in the pursuit of a particular goal, and even pursue a different goal, in order to regain energy for later pursuing the goal at hand. Likewise, one can use volition to regulate cognitive modes, for example, to overcome analytical means of apprehending a problem, in the service of intuitive approaches that might be more suited to it (Epstein, 2003).

Emotion regulation, which is subsumed here under volition, has been conceptualized in various ways (Koole, 2009). Some frameworks distinguish styles or types of emotion regulation, such as the distinction between reappraisal and suppression (Gross \& John, 2003). Other frameworks focus on the ability (or flexibility) to disengage from negative or intensify positive emotional states and concomitant thoughts in the service of goal pursuit (Beckmann \& Kuhl, 1984; Koole \& Jostmann, 2004; Kuhl, 1994; Quirin, Kuhl, \& Düsing, 2011). Measures of volitional emotion regulation are moderately related to neuroticism (Barańczuk, 2019; Diefendorff, Hall, Lord, \& Strean, 2000; Ng \& Diener, 2009; Southward, Altenburger, Moss, Cregg, \& Cheavens, 2018), which makes theoretical sense because the ability to regulate negative emotion will influence how frequently and intensely one experiences it (Lahey, 2009). However, in a DPA, we argue that one should distinguish descriptive traits from the underlying functions that may produce them. Therefore, one should distinguish processes involved in initial emotional reactivity from subsequent processes related to regulating those initial reactions, even though both are likely to contribute to neuroticism (Koole, 2009; Kuhl, 2000a; also Gross \& Feldman-Barrett, 2011).

\section{Critical remarks}

Among other contributions, the DPA highlights the fact that different research literatures typically focus on different psychological functions. In contrast to approaches focusing on one or a few specific functions, the DPA encourages investigating individual differences in multiple functions, in an integrated manner (refer to preceding discussion, Tenet 8). Ideally, this would involve all or most psychological functions (or at least classes of psychological functions) and detailed observations concerning the manner in which the different functions interact, whether in producing human behaviour or in predicting regularities in experience. That being said, we do not claim that our rough classification of psychological functions is the only one possible. Rather, we merely suggest that the present taxonomy into cognitive, emotionalmotivational, and volitional functions appears to be both plausible and useful (e.g. see Kuhl et al., 2020, for a taxonomy differentiating seven functional levels).

However, the DPA's focus on explaining personality by within-person functions and their interplay also implies the necessity of a multimethod approach (Robinson et al., 2019). This is important because questionnaire measures, both trait and state, are limited with respect to the identification and measurement of within-person psychological mechanisms (Robinson \& Wilkowski, 2015). Indeed, individuals are often unaware of the mechanisms that produce their behaviours (Wilson \& Dunn, 2004) and self-reports of processing or ability often correlate relatively weakly with objective indices of processing or ability (e.g. Mayer, Salovey, \& Caruso, 2008; Paulhus, Lysy, \& Yik, 1998). Hence, objective or indirect measures are necessary in assessing the mechanisms that we have highlighted (Tenet 10). Such measures may include neuroscientific assessments, which will be discussed subsequently.

\section{PHASES OF SELF-REGULATION}

We have already mentioned that the behaviour of self-regulating systems involves, at a minimum, the detection of distance from a goal and the engagement of an operator that can move the system toward the goal when a mismatch is detected. In most animals, and especially in ones as complicated as human beings, however, more functions or subsystems are required to characterize the process of control adequately. People must select between multiple goals and plan which of them will govern behaviour at which given moment. Often, they also must select which of multiple possible actions will be engaged to move toward a goal. Moreover, whereas some functions can work in parallel, such as implementing an automatic, well-learned behaviour and 
planning future actions, or unattended goal selection while consciously engaging in a different task (Dijksterhuis \& Nordgren, 2006), people typically have great difficulty engaging in two or more motor actions at the same time, if those are directed toward multiple goals. Moreover, some operations such as planning typically need to be accomplished before the action can be executed, and sometimes require a noticeable amount of time. Accordingly, self-regulation can be described in terms of a sequence of phases or stages, heuristically at least (Tenet 11) (DeYoung \& Weisberg, 2018; Kazén \& Quirin, 2017; Kuhl, 2000b; Kuhl et al., 2020). These phases necessitate the operating of specific functions, and individuals are assumed to differ in the degree to which they tend (or are able) to effectively use these functions during these phases, or to facilitate switching between them (e.g. use holistic processing during goal selection, or positive affect to facilitate action).

Self-regulation models have proposed various numbers of phases, depending on the degree of resolution of the complexity of the model and what phenomena they most directly aim to explain (DeYoung, 2015; Kuhl, 2000b; Van Egeren, 2009). Because we take these serial, phasic models to be necessarily heuristic, minor differences among them are unproblematic, as all conform to the same basic regulatory dynamics involved in the feedback control of human action. To illustrate the relevance of self-regulation phases in the DPA, we will here refer to the well-known Rubicon model of action phases (Heckhausen \& Gollwitzer, 1987) as it provides much common ground for the different models of self-regulation proposed. This model specifies four major phases (Figure 1): (i) goal selection phase, (ii) planning phase, (iii) action phase, and (iv) evaluation phase (for similar conceptualizations, see DeYoung, 2015; Kuhl, 1984).

In the first phase, individuals select a goal that will govern their behaviour. Goals are selected, consciously or nonconsciously, from various potentially competing candidates, on the basis of urges, preferences, situational cues, and utilitarian concerns that influence the activation level of goals. When a goal is sufficiently active, the person will attempt to select an action that will make progress toward the goal. If a promising action is considered but cannot immediately be implemented, a goal may be kept in memory in the form of an intention. After this second phase of action selection and planning, the individual takes initiative to perform the action when the situation is adequate (in contrast, procrastination would be one way a transition to the next stage can fail), which is continuously monitored by sensorimotor control processes during the third phase. In the fourth phase, the action and its outcomes (i.e. the current state) are interpreted and compared with the desired goal state. If a match is registered, the individual engages in a new goal selection, cycling back to Phase 1. By contrast, if the individual becomes aware of a mismatch, they revisit the action plan (planning) or disengage from the unmet goal (goal selection), and individual differences exist in the experience of a mismatch (error sensitivity) and the readiness with which goals are maintained or abandoned (e.g. Kuhl, 2000). Evaluative experiences concerning goal success, as well as what means were successful and which benefits and costs were experienced, can then be integrated in autobiographical memory to update

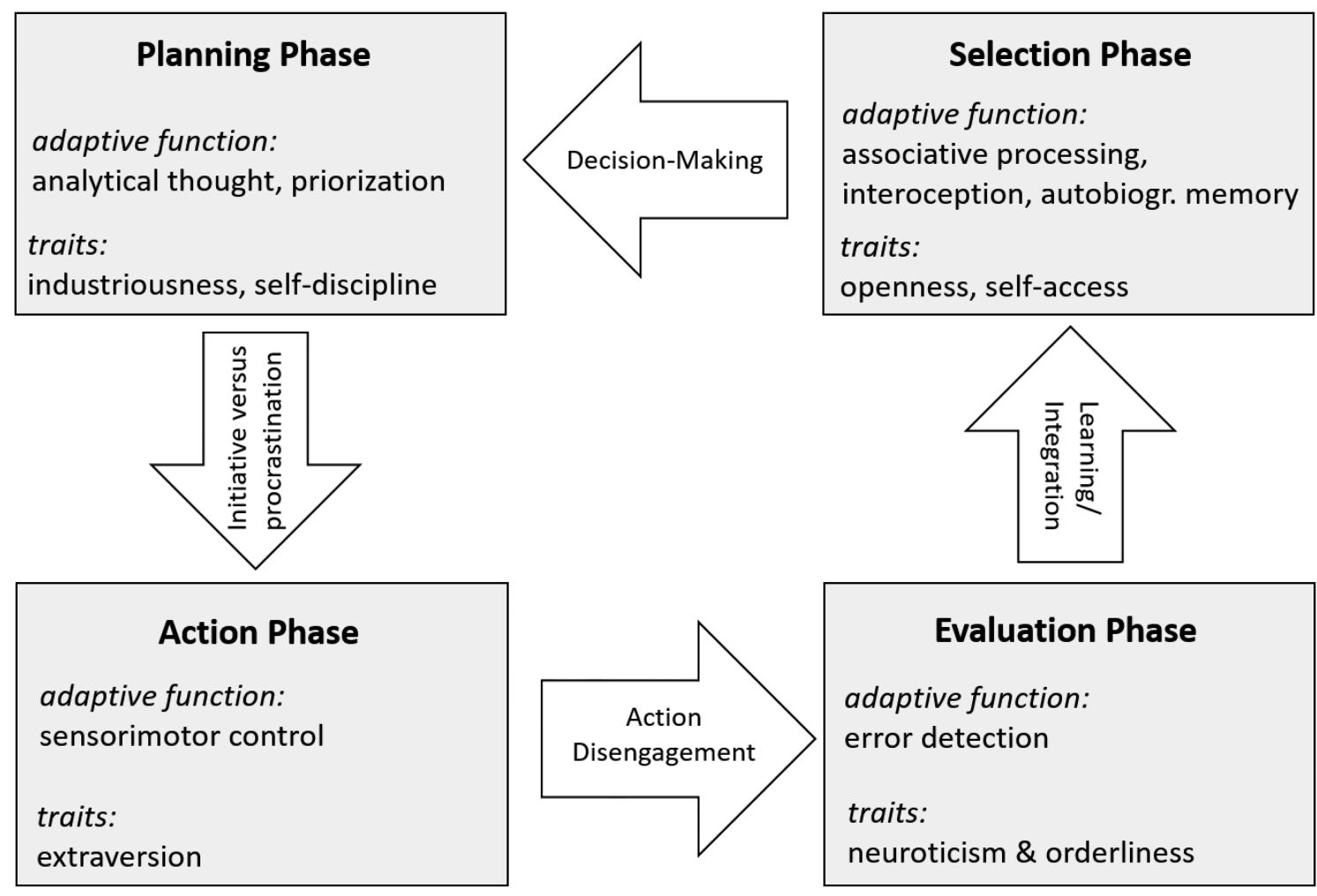

Figure 1. Dynamics of personality: phases of self-regulation, adaptive functions, and individual differences. 
the knowledge base for future goal and action selections, with individual differences existing in the readiness of updating (Tops, IJzerman, \& Quirin, 2020). In organizational contexts (March, 1991), the latter process has also been referred to as 'exploration', which contrasts with 'exploitation', primarily referring to the phases of planning and implementation.

Although error detection is described in the model as a separate phase between action and goal selection, in reality, the organism continuously carries out monitoring of potential discrepancies between expectations or desires and what is perceived. Becoming aware of these errors can thus interrupt all other stages, prompting conscious, focused attention toward discrepancies or even promote disengagement from a problematic goal (Brandstätter \& Herrmann, 2018; Kuhl, 1981), which constitutes one example of the heuristic nature of this model. Another example can be seen in the possibility that a goal might be abandoned without ever proceeding to action, if anticipatory evaluations of possible action outcomes, in the planning phase, leads to disengagement from an apparently unattainable goal.

\section{Psychological functions in self-regulation phases}

Emotional-motivational, cognitive, and volitional functions can be considered to have evolved to serve a particular purpose within the context of self-regulation, aiming to foster the attainment of goals. They are therefore of differing importance in different self-regulation phases (Tenet 12; Figure 1). For example, motivational aspects matter strongly in the goal selection phase, as preferences for different goals have to be weighed (Heckhausen \& Gollwitzer, 1987; Kuhl, 1984; Read, Smith, Droutman, \& Miller, 2017). By contrast, volitional functions come into play more heavily when a decision of a goal has been made and distractions or low levels of motivation render action planning, enactment, and goal maintenance difficult. With respect to low-level cognition, sensorimotor functions are inherently relevant to implementation in the action phase (Lehéricy et al., 2006; Takeshima \& Gyoba, 2014). Error awareness plays a particular role in the evaluation phase and is typically accompanied by an immediate negative emotional response upon conscious detection of a deviation from expectations in goal progress. As to high-level cognitive functions, broad holistic thought is often involved in taking many pros and cons of different goal alternatives simultaneously into consideration during the goal selection phase, whereas analytical thought is particularly important in the planning phase (Kuhl, 2000; Kuhl et al., 2020; Quirin et al., 2019).

Notably, moving from one self-regulation phase to the next, which entails a relative deactivation of functions strongly involved in one phase (e.g. analytical thought) and an activation of functions related to the next phase (Gollwitzer, 2012), is facilitated by volitional functions such as emotion regulation (Tenet 13; Kazén \& Quirin, 2017, for an overview). For example, the ability to flexibly upregulate positive emotions (in switching from planning to action) and to downregulate negative emotions (in detaching from error detection) ensures adaptive and smooth transitions between self-regulation phases and may thus foster everyday functioning and mental health (Kuhl, 2000a,b; Kuhl et al., 2020).

\section{Individual differences in self-regulation phases}

The DPA assumes a nomothetic structure of functional variables and operations that all humans share owing to evolution and also assumes that the functional requirements of that structure are summarized, in an important part, by the set of regulation phases just described (Tenet 14). Nevertheless, individual differences exist in the settings of functional parameters, and these create differences in personality. Accordingly, an understanding of general principles of psychological (i.e. cognitive, emotional-motivational, and volitional) functioning, which may be derived from psychological areas other than personality psychology, is imperative to an adequate understanding of individual differences (note that additional functional variables that are not human universals may exist in addition to such a nomothetic structure).

Sources of individual differences can be seen in the readiness with which individuals enter (or the steadiness with which they linger in) specific self-regulation phases (Tenet 15). For example, associative processing, interoceptive awareness of emotions and personal preferences ('self-access'; Quirin \& Kuhl, 2018), as well as accessibility of autobiographical memories are typically required for making adequate decisions. Therefore, openness to experience, which has been found to be associated with high capacity of these functions (Kaufman, 2013; Rasmussen \& Berntsen, 2010; Rosenberg et al., 2016), may be linked to the selection phase. By contrast, industriousness is conceptually linked to the planning phase of self-regulation and to ready engagement of related psychological functions such as prioritization and self-discipline. Moreover, evidence exists that individuals high in neuroticism engage more in error detection and linger in the evaluation phase, producing rumination (Whitmer \& Gotlib, 2013), which is also (likely) relevant to the orderliness aspect of conscientiousness (e.g. Yovel, Revelle, \& Mineka, 2005). As reported earlier, individuals high in extraversion may show faster sensorimotor processing as relevant for the action phase. Extraversion is also related to stronger responses to so-called reward prediction errors, in which the system detects that things have gone better than anticipated (e.g. Smillie et al., 2019; Wacker \& Smillie, 2015).

Individual differences can also derive from the engagement of different functions or mechanisms to produce outcomes in a specific self-regulation phase (Figure 1). For example, individuals may differ in their tendency to apply holistic (vs. analytical) thinking during goal selection, their tendency to be more or less perfectionistic in the planning phase, their tendency to linger in a state of action implementation, and their tendency to detect errors at smaller degrees of discrepancy between desired and observed states in the evaluation phase or to adequately update their experiential knowledge structure to avoid repetition errors (i.e. to learn). 
Neuroticism and extraversion are likely associated with sensitivity to mismatch in opposite directions, with neuroticism leading to greater sensitivity when outcomes are worse than expected, prompting negative affect, and extraversion leading to greater sensitivity when outcomes are better than expected, prompting positive affect (Rusting \& Larsen, 1997). Given that all biological systems have limited energy resources, it would not be adaptive to continuously engage operations to reduce very small discrepancies. Thus, some tolerance must be built into the system, and the error detection mechanism should not be too sensitive. How sensitive it should be, however, is presumably a question with no definite answer from an evolutionary perspective, as the optimal sensitivity values may fluctuate across environments, thereby preserving variance in the population (Nettle, 2006). This line of reasoning explains why the error detection threshold differs between individuals, in relation to both positive and negative mismatches, and thus sensitivity of the error system leads to individual difference in widely studied personality traits. Not least, it should be noted that this within-person functionality of emotions facilitating phase switches as mentioned previously may stimulate research in personality psychology to more intensely investigate interactions of neuroticism or extraversion with traits relating to volitional functions (Baumann, Kaschel, \& Kuhl, 2007; Robinson \& Gordon, 2011).

\section{INTERACTIONS AMONG FUNCTIONS: TEMPORAL AND SITUATIONAL DYNAMICS AND THEIR ASSESSMENT}

Systems constantly exchange information with their environments, which means that they obtain perceptual (and metabolic) inputs via a variety of channels and also themselves influence the environment by their behaviour. Behavioural outputs then feed back to create the individual's perception of resulting environmental changes and concomitant emotions and cognition. Accordingly, as a systems-theoretical approach, the DPA encompasses a personality-by-situations view by considering moment-to-moment transactions of individuals with situations (Tenet 16). This view is not new as influential originators of our discipline advocated its importance and recommended investigation of how behaviour varies within the person over time (Allport, 1937; Cattell, 1957; Lewin, 1935; Murray, 1938). Notwithstanding these early exhortations, a lack of large-scale methodologies to investigate occasions over time led researchers to focus primarily if not exclusively on between-person variables for many decades.

To investigate person-environment transactions systematically, one must understand the characteristics of situations and how they can affect psychological functions within an individual (Tenet 17). Therefore, personality researchers have begun to systematically and comprehensively taxonomize the psychological characteristics of situations that may transact with individuals' personality traits to produce experience and behaviour. For example, the DIAMONDS model (Rauthmann et al., 2014) encompasses eight continuous dimensions that can be used to characterize situations: Duty (work needs to be done), Intellect (intellectual engagement or problem solving is possible), Adversity (someone is under threat), Mating (potential mates can be courted), $\mathrm{pO}$ Sitivity (the situation encompasses or gives reason to expect rewards), Negativity (the situation could entail punishments and negative affect), Deception (mistrust could be an issue), and Sociality (meaningful social interactions are possible or relations can be built). Situation characteristics constitute affordances for arousing affective, motivational, cognitive, or volitional processes. The instruments developed on the basis of this taxonomy (e.g. Rauthmann et al., 2014) have already been used to describe, predict, or understand, for example, situations encapsulated in tweets (Serfass \& Sherman, 2015), changes of situations within and between people (Rauthmann \& Sherman, 2016), mean-level changes of situation characteristics across the lifespan (Brown \& Rauthmann, 2016), and affect and self-reported behaviours in experience sampling studies (Sherman, Rauthmann, Brown, Serfass, \& Jones, 2015).

Of special interest to the DPA are dynamic network modelling approaches to situations within everyday life, typically using the experience sampling method (Rauthmann \& Sherman, 2016; Sherman et al., 2015). In this method, participants are prompted by a smartphone app or another device to provide short ratings on their experience and behaviour at intervals across the day for some extent of time (e.g. several days or weeks) (e.g. Csikszentmihalyi \& Larson, 2014; Fleeson, 2012). Despite its advantages and potential as a DPA method (e.g. reduced retrospective memory biases, possibility to assess behavioural variability), experience sampling approaches possess some limitations that pose challenges for the DPA. First, the experience sampling method cannot easily be used to determine the causal relationships between two variables (although cross-lagged panel analyses can provide some evidence in this direction: Beck \& Jackson, 2019; Epskamp, Waldorp, Mõttus, \& Borsboom, 2018). Second, frequent responding in experience sampling may be challenging or simply not feasible for many participants. Third, many automatic processes and mechanisms cannot easily be assessed via self-report. Lastly, research that aggregates measures of psychological functions (e.g. affect) over time without taking their interactions among each other and with situational conditions in account cannot readily be subsumed under a DPA, given that the latter involves investigation of the causal structure of within-person processes. Complex parameters or dynamic indices may be preferable but also problematic in terms of the information they convey and their predictive abilities relative to simpler measurements like mean and standard deviation (e.g. Dejonckheere et al., 2019).

Given the limitations of the experience sampling methodology, a multimethod approach is necessary to potentiate insights into the dynamics of personality. Specifically, experimental research is enormously useful for investigating person-by-situation interactions (along with computational modelling, as discussed subsequently). In experiments, situations with specific characteristics (e.g. those described in the DIAMONDS model) may be manipulated and interactive 
effects of personality on affective-motivational, cognitive, or volitional responses may be investigated. For example, experiments have been used to dissociate facets of broad factors such as extraversion (Depue \& Morrone-Strupinsky, 2005; Revelle, Humphreys, Simon, \& Gilliland, 1980), validate measures of motives (McClelland, 1985), and investigate the cognitive mechanisms underlying personality traits (e.g. Moeller, Robinson, \& Bresin, 2010; Robinson et al., 2019; Smillie et al., 2016), as well as emotion regulation abilities (Radtke, Düsing, Kuhl, Tops, \& Quirin, 2020; Quirin et al., 2011) and strategies (Gross, 2014; Gross \& John, 2003).

\section{THE IMPORTANCE OF NEUROSCIENTIFIC EVIDENCE}

As the brain is the primary material generator of mental processes, personality functioning included, neuroscientific insights are helpful for advancing our understanding of the causal network structure of human personality (Tenet 18). Specifically, empirical evidence on how the structure and function of brain systems are linked to psychological constructs and to individual variation in them can help us identify which variables must be distinguished and what functions may explain reasonable amounts of variance in human behaviour (Allen \& DeYoung, 2017). An early example of this principle in action is that insights into the functioning of the brain (e.g. action potentials) acted as a source of inspiration for later artificial neural networks (Hebb, 1949). At the same time, insights into brain functioning can put boundaries on theoretically possible mechanisms underlying personality and thus channel our hypotheses on personality functioning into a meaningful direction.

It should be noted that, although very useful, neuroscientific research is not necessary for theory development in personality research, a statement that follows from the systems-theoretical principle that functional causal networks can largely be abstracted from the material substrate (e.g. neural structures) that instantiates it. Accordingly, the causal network of mechanisms underlying personality may be deciphered by other means as well, using measurement of psychological characteristics (through both introspective and external observations of behaviour) and their dynamic computer simulation (refer to succeeding discussion). Nonetheless, the DPA is compatible with neuroscience and can be used to develop models that are consistent with current neuroscientific knowledge (e.g. Allen \& DeYoung, 2017). Generally, the authors agree that DPA models should be in accordance, at least at some level of abstraction, with what is known about human brain functioning.

A more specific benefit of neuroscience for the DPA derives from the fact that the same kind of overt behaviour may stem from different underlying functions on different occasions (Tenet 19) (Funder, 1991). The studies on the relationship between extraversion and sensorimotor functioning mentioned previously (De Pascalis et al., 2018; Stahl \& Rammsayer, 2008) provide a good example because they could identify sensorimotor differences for introverted versus extraverted individuals via electroencephalography but not via behavioural measures such as reaction times or self-reports. Accordingly, neuroscientific research can advance our knowledge about functions that need to be differentiated in explaining personality when mere self-report or observation will not suffice. In this vein, patterns of brain activation and knowledge about their associated psychological functions can be considered objective data that may, sometimes at least (Poldrack, 2011), measure the operation of a function and their underlying systems more readily than behavioural assessments can. In addition to brain activation patterns, some functions may be measured with implicit measures of cognition, motivation, and affect (e.g. Kazén et al., 2015; Quirin, Kazén, \& Kuhl, 2009), but these can also be combined with assessment of brain activation for cross validation (e.g. Quirin \& Lane, 2012; Suslow et al., 2015).

Two recent developments in human neuroscience are particularly compatible with the DPA. The first is a shift from a region-oriented to a network-oriented approach. Instead of approaching the brain in terms of specific regions assumed to carry out computations for specific tasks, researchers are increasingly recognizing that many psychological functions are carried out by distributed networks of regions that operate in relative synchrony-which are termed large-scale brain networks. Many of these networks are evident in patterns of synchrony (known as functional connectivity) regardless of whether the person is at rest or engaged in various tasks (Krienen, Yeo, \& Buckner, 2014). In addition, some broad networks have been identified in many distinct contexts, have known associations with broad psychological functions, and can be used as a common atlas for human neuroscience (Uddin, Yeo, \& Spreng, 2019).

This scheme is highly compatible with the DPA, which asserts that psychological functioning can be parsed in terms of a set of broad regulatory functions (e.g. prioritizing goals and monitoring for errors) that are important for the pursuit of goals, no matter which goal is being pursued (although note that different goals may additionally recruit more specific mechanisms or modules that are specialized for the type of goal in question). Thus, one fruitful DPA would be to identify psychological functions that link specific traits with specific neural networks, such as with respect to the hypothesis that conscientiousness depends on a neural network that specializes in prioritizing goals (Rueter, Abram, MacDonald, Rustichini, \& DeYoung, 2018). Because of its relevance for personality functioning, large-scale brain networks have been considered to underlie so-called personality systems (Quirin et al., 2019; also Tops, Quirin, Boksem, \& Koole, 2017).

The second major development is a move toward focusing on predictive processing as the basis of virtually all brain function. This approach is described in different models by terms like predictive coding, predictive control, or the Bayesian brain (e.g. Clark, 2013; Fitch, 2014; Rao \& Ballard, 1999). These models postulate that, at every level of the brain's hierarchical organization, neural structures predict bottom-up input (i.e. from structures closer to sensory input) and themselves send signals to higher levels 
of organization only inasmuch as the actual input differs from the predicted input. This allows efficient information processing because only deviations from expectations require additional processing. At the functional level, we can say that the brain anticipates sensory inputs on the basis of both pre-existing perceptual expectations and goals for desired perceptual states. These schemata form the priors that are used to make predictions (Tops et al., 2010). Accordingly, the brain is continuously concerned with minimizing 'prediction errors' rather than with representing the world in some more comprehensive manner. It continuously monitors the external and internal environment for information that is discrepant with its schemata (i.e. for prediction errors, with most of them not becoming consciously available to the individual).

Predictive processing can be found across many different levels of organization in the brain, ranging from communication between adjacent sections of cortex all the way up to interactions among large-scale networks and structures. Thus, predictive coding and its associated feedback circuits are considered not only to play a role in low-level cognition such as perception and sensorimotor function (Franklin \& Wolpert, 2011) but to constitute a much more general systems-theoretical principle of the brain (e.g. Friston, 2005). As such, predictive coding can be usefully applied in explaining phenomena such as mismatch sensitivity in language processing (e.g. Friederici, Pfeifer, \& Hahne, 1993) as well as reward processing as mediated by mesocorticolimbic dopamine release (Schultz, 2013). Similarly, Gray and McNaughton (2000) have argued that, at one of the highest levels of functional organization, a network centred on the hippocampus serves as a comparator to detect potential conflicts between psychological goals, a central mechanism implicated in behavioural inhibition and neuroticism (Allen \& DeYoung, 2017). However, it should be noted that not all prediction errors (e.g. at the level of basic motor or perceptual processes) are relevant to the more complex psychological functions associated with these personality dimensions.

In the context of such broad principles, it is important to note that individual differences in psychological traits may stem from variation in a wide range of neural parameters. These include patterns of connectivity and interaction within or between networks at both structural and functional levels, the computational efficiency of different networks, and variations in neurotransmitter functioning (which can be related to the synthesis and metabolism of the neurotransmitter in question and to the density, distribution, and efficiency of its receptors). Undoubtedly, there are many other categories of neural parameters in which variation could also be consequential for variations in personality. An important principle when considering the sources of personality traits in brain function is that they will have a many-to-many mapping (Allen \& DeYoung, 2017; Yarkoni, 2015). That is, any given neural parameter may affect multiple psychological functions (which in turn may contribute to multiple broad personality traits), and any given personality trait is likely to reflect a combination of multiple psychological functions and variation in even more neural parameters.

\section{AN EXAMPLE OF A DPA ANALYSIS: THE CASE OF ERROR DETECTION, NEGATIVE EMOTION, NEUROTICISM, AND EMOTION REGULATION}

To illustrate how the DPA, as an inherently functional approach, applies to research across psychological and neurobiological levels of analysis, we focus on an example from a specific phase of self-regulation: the comparison of the present state to the desired state in the evaluation phase. This involves detecting mismatches between the current perceived state and the various goals of the individual, which can be described as 'error detection', a function that has been extensively investigated using neuroscientific methods.

At any given moment, individuals expect to experience a particular set of perceptions, based simultaneously on a model of the likely conditions of the world and a model of the desired state of the world, entailing goal states of the individual. Errors can come in the form of deviation from expectations stemming from either model. In cybernetic terms, errors are threats because they signal an increase in uncertainty regarding whether the system will be able to reach its goals. Uncertainty is therefore innately threatening (although also innately promising, as a cue for exploration: Berlyne, 1960; DeYoung, 2013; Heine, Proulx, \& Vohs, 2006; Jonas et al., 2014). Variation in the sensitivity of error detection should therefore be correlated with variation in defensive reactions to uncertainty, threat, and punishment.

The psychological core of such defensive reactions is negative emotions, and a general tendency to experience negative emotions of all kinds has long been recognized as a major dimension of personality, with labels such as neuroticism, negative emotionality, and dispositional negativity, which all refer to the notion that people who are prone to experience one negative emotion also tend to be prone to experience various other negative emotions (DeYoung, 2015; Shackman et al., 2016). One potential explanation for this general tendency is precisely that all such emotions ultimately stem from error detection. Consistent with the idea that neuroticism is associated with uncertainty aversion, one electroencephalographic study found that individuals high in neuroticism had a neural reaction to ambiguous feedback about task performance that was even stronger than their response to negative feedback, whereas the opposite was true for individuals low in neuroticism (Hirsh \& Inzlicht, 2008). In general, persons with high levels of internalizing (a general risk for disorders like anxiety and depression that is difficult to distinguish from neuroticism statistically: Griffith et al., 2010) appear to display higher error detection sensitivity, as indexed by electroencephalography (Olvet \& Hajcak, 2008).

Of course, any specific negative emotion involves additional features that differentiate it from other negative emotions. This illustrates the concept of trait hierarchy, in this case pertaining to emotion, in which more specific traits (often called 'facets') have unique causes as well as causes shared with other related traits (e.g. sadness and guilt both join a general negative affect factor but are distinct from each other: Watson, 2000). Further, the causes of any specific trait 
are likely to be multi-determined as well. For example, anxiety is one specific negative emotion related to uncertainty, which involves increased vigilance, the involuntary inhibition of behaviour, and the increased arousal of the sympathetic nervous system, all of which have distinct, identifiable neural circuits (Gray \& McNaughton, 2000). Variations in trait levels of anxiety could thus derive from differences in any of these circuits (Shackman et al., 2016).

Nonetheless, specific limbic structures, and especially the hippocampus and amygdala, have been implicated in the detection of error or conflict and the mobilization of subsequent negative emotional responses, respectively, and they are likely to be implicated in neuroticism. Consistent with this idea, several imaging studies have found that neuroticism is positively associated with amygdala activation during tasks involving threatening, uncertain, or ambiguous stimuli (e.g. Everaerd, Klumpers, van Wingen, Tendolkar, \& Fernández, 2015). A meta-analysis also found that neuroticism was positively associated with hippocampal activation during fear learning (Servaas et al., 2013), and several small positron emission tomography studies have found a link between resting-state hippocampal activity and neuroticism (e.g. Gray \& McNaughton, 2000). Encouragingly, as an example of cross-species validation, a study of 238 rhesus monkeys similarly found that anxious temperament predicted metabolic activity in the hippocampus (Oler et al., 2010).

Functional magnetic resonance imaging (MRI) studies further suggest the relevance of interactions between the amygdala and medial prefrontal cortex (presumably reflecting emotion regulation). A recent study of over 500 individuals showed that connectivity between these regions in response to images of faces expressing negative emotion (a common tool used to activate the amygdala) was negatively correlated with neuroticism (Silverman et al., 2019). MRI studies of structural connectivity have also supported the idea that reduced influence of prefrontal structures on limbic structures is one component of neuroticism, consistently finding a pattern of reduced white matter coherence in axonal tracts connecting cortical and subcortical regions (e.g. Bjørnebekk et al., 2013).

The conjunction of functional and structural evidence suggests that one crucial component of the neural substrate of (reduced) neuroticism may be the brain systems that downregulate defensive emotional responses after they have been triggered by threatening stimuli-that is, emotion regulation abilities or 'emotional flexibility'. Accordingly, and as described earlier, negative emotion sensitivity (strongly linked to the process of error detection) and emotion regulation abilities (here operationalized in terms of individual differences in the modulatory processes that follow error detection) may be considered two different components of neuroticism. This functional dissociation allows for a person to possess both high negative emotion sensitivity and high emotion regulation abilities, which, perhaps paradoxically, has predicted especially high levels of well-being in correlational studies (Baumann et al., 2007).

Emotion regulation abilities can be assumed to involve regions of prefrontal cortex and the adjacent anterior cingulate cortex - structures that typically show regulatory influences on the amygdala (Marusak et al., 2016; Silverman et al., 2019). Because measures of emotion regulation and neuroticism are typically substantially negatively correlated (and poor emotion regulation may be considered a component of neuroticism, although rarely measured as one of its facets), the fact that neuroticism is related to reduced connectivity between the amygdala and the prefrontal cortex may be attributed to low emotion regulation abilities in individuals with high neuroticism (e.g. Servaas et al., 2013). In fact, Schlüter et al. (2018) found that emotion regulation abilities predicted increased connectivity between the dorsal anterior cingulate and the amygdala. Similarly, Morawetz, Bode, Derntl, and Heekeren (2017) demonstrated that success in emotion regulation (in terms of reappraisal) predicted increased connectivity between areas related to both emotion regulation (e.g. inferior frontal gyrus and ventromedial prefrontal cortex) and areas related to emotion sensitivity (e.g. amygdala). These findings are promising and they demonstrate the potential of the DPA, which (among other things) considers the manner in which different functions combine to determine psychological outcomes. Nonetheless, more research is needed to substantiate the incremental predictive power of emotion regulation abilities over measures of emotion sensitivity in both behavioural and brain research.

\section{IMPORTANCE OF COMPUTATIONAL MODELLING}

From the DPA perspective, nearly all methods applied by personality psychologists (e.g. correlational and experimental methods, third-person observation and introspection, or even evolutionary considerations) can help to uncover the processes and mechanisms that are causal for personality functioning, and each has a distinct significance for different problems. Here, however, we would like to highlight computational modelling as a method for the DPA. Computational modelling can help to decipher the causal network of mechanisms underlying personality and the variability of behaviour (Tenet 20). Complex self-regulating systems typically consist of non-linear relationships, multiple causal factors (including person-by-situation interactions), and feedback loops between antecedents and consequences. These features result in a complexity of mutually influencing variables that readily leads to dynamic behavioural outcomes surpassing the predictive potential of static, linear models, as were almost exclusively used to predict behaviour during the last few decades of personality research. Computational modelling has been developed to deal with these complexities and can therefore be considered a prime method for the DPA.

Computational modelling builds upon principles of structural and quantitative system analyses by creating a mathematical formulation of the causal relationships between variables that can be used as the foundation of a computer simulation. Computer simulation then tests which output the system produces as a function of given systems' inputs and parameters. Computer models can be instantiated in a variety of computational architectures such as cybernetic 
control systems models (e.g. Bischof, 1975; Powers, 1973; Schneider, 2015), neural network models (O'Reilly, Munakata, Frank, Hazy, \& Contributors, 2012; Rumelhart et al., 1986), or hybrids of these two (e.g. Hunt, Sbarbaro, Żbikowski, \& Gawthrop, 1992; Nguyen \& Widrow, 1990). Computational modelling has already been used to simulate human personality by models instantiated on the basis of cybernetic (Atkinson \& Birch, 1970; Kuhl \& Atkinson, 1986; Revelle \& Condon, 2015) or neural networks (Read et al., 2010).

In computational modelling, the researcher typically begins by specifying hypotheses about the topological structure of causal relationships (e.g. as illustrated by signal flow graphs). Because of the dynamic complexities of interacting variables, these hypotheses need to be examined by the simulation of human behaviour using mathematical elaborations of the functional relationships, which results in time series of the values of all the variables involved (i.e. input, psychological, and output variables). If the resulting system output (behaviour) does not readily match the outcome expected by the researchers, the researchers can make changes in the topological structure of the relationships or their parameters until an acceptable fit is obtained. If such a fit is obtained, the constructed structure of the model provides a likely account of the causal relationships underlying personality functioning. However, if plausible adjustments cannot be made to the model that result in acceptable fit, then this state of affairs argues against the model. Such procedures can also be used to compare different DPA models with respect to their veridicality (Costantini \& Perugini, 2018).

Ideally, predicted behaviour can be compared with empirically assessed data on dynamics of personality such as time series of observable (i.e. output) variables as recorded by ambulatory diaries or experience sampling (e.g. Csikszentmihalyi \& Larson, 2014; Fleeson, 2012; Geukes, Nestler, Hutteman, Küfner, \& Back, 2017; Kuhl, Mitina, \& Koole, 2017), or continuous recordings of physiological or behavioural (e.g. movement) data. The fit between that empirical data and outputs produced by the computerized model can then be evaluated visually or using various fit indices (e.g. Pickering \& Pesola, 2014). Today, more so than before, the possibility of gathering large samples of individuals' experience and behaviour over time (e.g. smartphone and other electronic diaries) makes it possible to compare computer simulations to big-data sets to test the adequacy and accuracy of the simulation, as well as to continuously adapt the parameters of a concrete DPA model and to refine it subsequently.

Here, we present the virtual personality model (Read, Smith, et al., 2017) as an example of a concrete computational DPA model. This model uses basic motivational principles to predict behaviour on the basis of directed information flow between nodes in a neural network. Thus, it can be seen as a mathematical description of the functioning of a set of interconnected nodes that pass activation to each other over weighted links (e.g. O'Reilly et al., 2012).

In this model, nodes represent human subsystems constituting important psychological functions that are arranged in three operational layers, intermediated by hidden layers.
Specifically, in the first input layer, nodes represent situational cues and internal states that are associated with two major motivational systems, reward (approach) and punishment (avoidance), situated on a second layer. Situational cues identify affordances that indicate the possibility to advance goals that can activate one of these two systems or even both (e.g. a novel social situation may induce mixed emotions of threat and reward as the individual may be rejected or accepted). And internal state cues identify the status of both physical and emotional needs. Within the reward and punishment motivation systems, different types of motives are nested, such as hunger, affiliation (e.g. attachment), or power. Accordingly, signals from internal states indicating a certain need and signals from situational cues (indicating their incentive value) together activate motive-specific motivational systems. Different cues and internal states can be activated in parallel and, thus, activate multiple motives that then compete for behaviour, with the strongest motive prevailing (e.g. Atkinson \& Birch, 1970; see Revelle \& Condon, 2015, for a conceptually similar approach).

Strongly activated motives in the two motive system layers then activate behaviour(s) in a third behaviour layer, where the behaviours aim at either approaching or avoiding a goal (e.g. Hull, 1943). One way in which individual differences can be represented is by differing strengths of specific motive goals and by baseline activations of these two motive systems (Read, Brown, Wang, \& Miller, 2018). As behaviour may successfully arrive at the consummation of a goal (e.g. obtaining warmth by a person), behaviour influences in a feedback control loop consult the availability of situational cues (e.g. when the other person distances after some intimate contact) and one's internal state (e.g. reduction of need for security, or even subsequent increase if the other person distances). By using different parameters for baseline activations of the motive systems and by producing dynamics in behaviour, this computational model can explain how stability of between-person variance in personality factor domains such as assertiveness (power) or affiliation can be logically integrated with the occurrence of within-person variability over time and across situations (see Read, Droutman, \& Miller, 2017, for such an application).

Note that although the model uses feedback control (as behaviour feeds back to changes in the availability of external rewards and interoceptive states), it does not rely on unchanging reference points that indicate full goal attainment. Rather, the values in the network (e.g. goal activations) settle in a range of points as a function of multiple constraints deriving from many parallel goals and other parameters of the system. A major reason for such a conceptualization can be seen in the fact that this model primarily relies on the activation of nodes representing motivational functions or strengths to drive behaviour and does not include cognitive components explicitly comparing the current state with a reference value in order to prioritize the different goals using volitional functions.

Whereas the virtual personality model is an appealing computer model that implements some motivational (e.g. approach and avoidance) and cognitive functions (i.e. goal 
representation) as well as individual differences in them, it does not consider other cognitive functions such as holistic versus analytical processing or volitional functions. Accordingly, goal selection in this model (much like animal models) is based on the momentary strength of action preferences. Other models highlight volitional functions for the goal selection phase, which facilitate the prioritization of abstract, integrated values over motivational strivings, such as via goal shielding or holistically integrating the latter with motivational strivings on the basis of multiple constraint satisfaction processes as a key feature of parallel processing (Engel \& Kuhl, 2015; Kuhl et al., 2020; Kuhl, Koole, \& Quirin, 2015). Future research might attempt to integrate different, yet not incompatible models to arrive at an integrative computational DPA model that considers the different levels of cognitive, motivational, and volitional functions, the interplay of which is considered to make up an individual's personality.

\section{CONCLUSION}

The DPA approach refers to a systems-theoretical conceptualization of personality functioning that considers individual differences in basic and higher-level cognitive, emotionalmotivational, and volitional functions related to selfregulation. We highlighted 20 tenets that we deem useful to consider when conducting DPA research, which we derived from the commonalities we identified among models proposed by the authors and by others. The DPA seeks to explain the causal underpinnings of personality by analysing the network of within-person psychological functions. It thus complements the descriptive, between-person trait approach, and even has the potential to explain between-person variability in personality and behaviour. Advancements in this endeavour can strongly benefit from the consideration of multiple methods besides questionnaires such as experience sampling, objective assessment, computational modelling, experimental research, and neurobiological methods. The DPA has the potential to strongly connect personality research with neighbouring disciplines such as general, social, and clinical psychology, as well as the neurosciences.

\section{ACKNOWLEDGEMENT}

This work was facilitated by a grant from Templeton Rlg. Trust (TRT 0119) supporting M. Q. Open access funding enabled and organized by Projekt DEAL.

\section{REFERENCES}

Allen, T. A., \& DeYoung, C. G.Widiger, T. A. (Eds.). (2017). Personality neuroscience and the five factor model. The Oxford handbook of the Five Factor Model (pp. 1-63). New York, NY, USA: Oxford University Press.

Allport, G. W. (1937). Personality: A psychological interpretation. New York, NY, USA: Holt.
Anderson, J. R. (1983). The architecture of cognition. Hillsdale, NJ, USA: Lawrence Erlbaum Associates, Inc.

Atkinson, J. W., \& Birch, D. (1970). On the dynamics of action. Nederlands Tijdschrift voor de Psychologie en haar Grensgebieden, 25, 83-94.

Barańczuk, U. (2019). The five factor model of personality and emotion regulation: A meta-analysis. Personality and Individual Differences, 139, 217-227.

Baumann, N., Kaschel, R., \& Kuhl, J. (2007). Affect sensitivity and affect regulation in dealing with positive and negative affect. Journal of Research in Personality, 41, 239-248. https://doi. org/10.1016/j.jrp.2006.05.002

Baumeister, R. F. (2014). Self-regulation, ego depletion, and inhibition. Neuropsychologia, 65, 313-319.

Baumert, A., Schmitt, M., Perugini, M., Johnson, W., Blum, G., Borkenau, P., ... Wrzus, C. (2017). Integrating personality structure, personality process, and personality development. European Journal of Personality, 31, 503-528. https://doi.org/10.1002/ per.2115

Beck, E. D., \& Jackson, J. J. (2019). Consistency and change in idiographic personality: A longitudinal ESM network study. Journal of Personality and Social Psychology. Advance online publication, 118, 1080-1100. https://doi.org/10.1037/ pspp0000249

Beckmann, J., \& Kuhl, J. (1984). Altering information to gain action control: Functional aspects of human information processing in decision making. Journal of Research in Personality, 18, 224-237. https://doi.org/10.1016/0092-6566 (84)90031-X

Berlyne, D. E. (1960). Conflict, arousal, and curiosity. New York, NY, USA: McGraw-Hill. https://doi.org/10.1037/11164-000.

Berridge, K. C. (2007). The debate over dopamine's role in reward: The case for incentive salience. Psychopharmacology, 191, 391-431.

Bischof, N. (1975). A systems approach towards the functional connections of attachment and fear. Child Development, 46, 801-817. https://doi.org/10.2307/1128384

Bischof, N. (2016). Struktur und Bedeutung: Einführung in die Systemtheorie [Structure and meaning: Introduction in systems theory]. Goettingen, Germany: Hogrefe.

Bjørnebekk, A., Fjell, A. M., Walhovd, K. B., Grydeland, H., Torgersen, S., \& Westlye, L. T. (2013). Neuronal correlates of the five factor model (FFM) of human personality: Multimodal imaging in a large healthy sample. NeuroImage, 65, 194-208. https://doi.org/10.1016/j.neuroimage.2012.10.009

Block, J. (1995). A contrarian view of the five-factor approach to personality description. Psychological Bulletin, 117, 187-215. https://doi.org/10.1037/0033-2909.117.2.187

Boccia, M., Piccardi, L., Di Marco, M., Pizzamiglio, L., \& Guariglia, C. (2016). Does field independence predict visuo-spatial abilities underpinning human navigation? Behavioural evidence. Experimental Brain Research, 234, 2799-2807. https://doi.org/10.1007/s00221-016-4682-9

Brandstätter, V., \& Herrmann, M. (2018). Goal disengagement and action crises. In N. Baumann, M. Kazén, M. Quirin, \& S. L. Koole (Eds.), Why people do the things they do (pp. 87-108). Goettingen, Germany: Hogrefe Publishing.

Brown, N. A., \& Rauthmann, J. F. (2016). Situation characteristics are age graded: Mean-level patterns of the situational eight DIAMONDS across the life span. Social Psychological and Personality Science, 7, 667-679. https://doi.org/10.1177/ 1948550616652207

Carver, C. S., \& Scheier, M. F. (Eds) (1998). On the self-regulation of behavior. New York, NY, USA: Cambridge University Press. https://doi.org/10.1017/CBO9781139174794.

Cattell, R. B. (1957). Personality and motivation structure and measurement. Chicago, IL, USA: World Book Co.

Cervone, D., \& Shoda, Y. (1999). The coherence of personality: Social-cognitive bases of consistency, variability, and organization. New York, NY, USA: Guilford Press. 
Clark, A. (2013). Whatever next? Predictive brains, situated agents, and the future of cognitive science. Behavioral and Brain Sciences, 36, 181-204. https://doi.org/10.1017/ S0140525X12000477

Cohen, J. B., \& Andrade, E. B. (2004). Affective intuition and task-contingent affect regulation. Journal of Consumer Research, 31, 358-367. https://doi.org/10.1086/422114

Collins, M. D., Jackson, C. J., Walker, B. R., O'connor, P. J., \& Gardiner, E. (2017). Integrating the context-appropriate balanced attention model and reinforcement sensitivity theory: Towards a domain-general personality process model. Psychological Bulletin, 143, 91-107.

Corr, P. J. (2004). Reinforcement sensitivity theory and personality. Neuroscience \& Biobehavioral Reviews, 28, 317-332. https:// doi.org/10.1016/j.neubiorev.2004.01.005

Corr, P. J. (2020). A consensual paradigm for personality: Introduction to special issue. Personality and Individual Differences, 152, 109611. https://doi.org/10.1016/j.paid.2019.109611

Costantini, G., \& Perugini, M. (2018). A framework for testing causality in personality research. European Journal of Personality, 32, 254-268. https://doi.org/10.1002/per.2150

Cottini, M., \& Meier, B. (2020). Prospective memory monitoring and aftereffects of deactivated intentions across the lifespan. Cognitive Development, 53, 100844. https://doi.org/10.1016/j. cogdev.2019.100844

Csikszentmihalyi, M., \& Larson, R. (2014). Validity and reliability of the experience-sampling method. In M. Csikszentmihalyi (Ed.), Flow and the foundations of positive psychology (pp. 35-54). Dordrecht, The Netherlands: Springer.

Davis, J. K., \& Cochran, K. F. (2017). An information processing view of field dependence-independence 1. In O. N. Saracho (Ed.), Cognitive style in early education (pp. 61-78). London, UK: Routledge. https://doi.org/10.4324/9781315209968-4.

De Pascalis, V., Sommer, K., \& Scacchia, P. (2018). Extraversion and behavioural approach system in stimulus analysis and motor response initiation. Biological Psychology, 137, 91-106. https:// doi.org/10.1016/j.biopsycho.2018.07.004

Deci, E. L., \& Ryan, R. M. (2011). Levels of analysis, regnant causes of behavior and well-being: The role of psychological needs. Psychological Inquiry, 22, 17-22. https://doi.org/ 10.1080/1047840X.2011.545978

Dejonckheere, E., Mestdagh, M., Houben, M., Rutten, I., Sels, L., Kuppens, P., \& Tuerlinckx, F. (2019). Complex affect dynamics add limited information to the prediction of psychological wellbeing. Nature Human Behaviour, 3, 478-491.

Depue, R. A., \& Morrone-Strupinsky, J. V. (2005). A neurobehavioral model of affiliative bonding: Implications for conceptualizing a human trait of affiliation. Behavioral and Brain Sciences, 28, 313-395.

DeYoung, C. G. (2013). The neuromodulator of exploration: A unifying theory of the role of dopamine in personality. Frontiers in Human Neuroscience, 7. https://doi.org/10.3389/ fnhum.2013.00762

DeYoung, C. G. (2015). Cybernetic Big Five theory. Journal of Research in Personality, 56, 33-58. https://doi.org/10.1016/j. jrp.2014.07.004

DeYoung, C. G., \& Krueger, R. F. (2018). A cybernetic theory of psychopathology. Psychological Inquiry. A cybernetic theory of psychopathology, 29, 117-138.

DeYoung, C. G., \& Weisberg, Y. J. (2018). Cybernetic approaches to personality and social behavior. In M. Snyder, \& K. Deaux (Eds.), The Oxford handbook of personality and social psychology (2nd ed., pp. 387-414). New York, NY, USA: Oxford University Press.

Diefendorff, J. M., Hall, R. J., Lord, R. G., \& Strean, M. L. (2000). Action-state orientation: Construct validity of a revised measure and its relationship to work-related variables. Journal of Applied Psychology, 85, 250-263. https://doi.org/10.1037/00219010.85.2.250
Dijksterhuis, A., \& Nordgren, L. F. (2006). A theory of unconscious thought. Perspectives on Psychological Science, 1, 95-109. https://doi.org/10.1111/j.1745-6916.2006.00007.x

Dumas, G., Nadel, J., Soussignan, R., Martinerie, J., \& Garnero, L. (2010). Inter-brain synchronization during social interaction. PLoS ONE, 5, e12166. https://doi.org/10.1371/journal. pone.0012166

Easterbrook, J. A. (1959). The effect of emotion on cue utilization and the organization of behavior. Psychological Review, 66, 183-201. https://doi.org/10.1037/h0047707

Elliot, A. J., \& Fryer, J. W. (2008). The goal construct in psychology. In J. Y. Shah, \& W. L. Gardner (Eds.), Handbook of motivation science (pp. 235-250). New York, NY, USA: Guilford Press.

Endedijk, H. M., Meyer, M., Bekkering, H., Cillessen, A. H. N., \& Hunnius, S. (2017). Neural mirroring and social interaction: Motor system involvement during action observation relates to early peer cooperation. Developmental Cognitive Neuroscience, 24, 33-41. https://doi.org/10.1016/j.den.2017.01.001

Engel, A., \& Kuhl, J. (2015). Personality and planning: The interplay between linear and holistic processing. In M. D. Mumford, \& M. Frese (Eds.), The psychology of planning (pp. 58-88). Boston, Mass.: Routledge, Taylor and Francis Group.

Epskamp, S., Waldorp, L. J., Mõttus, R., \& Borsboom, D. (2018). The Gaussian graphical model in cross-sectional and time-series data. Multivariate Behavioral Research, 53, 453-480. https:// doi.org/10.1080/00273171.2018.1454823

Epstein, S. (2003). Cognitive-experiential self-theory of personality. In T. Millon, \& M. J. Lerner (Eds.), Comprehensive handbook of psychology: Personality and social psychology (pp. 159-184), 5. Hoboken, NJ, USA: Wiley \& Sons. https://doi.org/10.1002/ 0471264385.wei0507.

Everaerd, D., Klumpers, F., van Wingen, G., Tendolkar, I., \& Fernández, G. (2015). Association between neuroticism and amygdala responsivity emerges under stressful conditions. NeuroImage, 112, 218-224.

Fajkowska, M. (2015). The complex-system approach to personality: Main theoretical assumptions. Journal of Research in Personality, 56, 15-32.

Fitch, W. T. (2014). Toward a computational framework for cognitive biology: Unifying approaches from cognitive neuroscience and comparative cognition. Physics of Life Reviews, 11, 329-364. https://doi.org/10.1016/j.plrev.2014.04.005

Fleeson, W. (2012). Perspectives on the person: Rapid growth and opportunities for integration. In K. Deaux, \& M. Snyder (Eds.), The Oxford handbook of personality and social psychology (pp. 33-63). New York, NY, USA: Oxford University Press.

Franklin, D. W., \& Wolpert, D. M. (2011). Computational mechanisms of sensorimotor control. Neuron, 72, 425-442. https:// doi.org/10.1016/j.neuron.2011.10.006

Fredrickson, B. L. (2001). The role of positive emotions in positive psychology: The broaden-and-build theory of positive emotions. American Psychologist, 56, 218-226. https://doi.org/10.1037/ 0003-066X.56.3.218

Friederici, A. D., Pfeifer, E., \& Hahne, A. (1993). Event-related brain potentials during natural speech processing: Effects of semantic, morphological and syntactic violations. Cognitive Brain Research, 1, 183-192. https://doi.org/10.1016/0926-6410 (93)90026-2

Frijda, N. H. (2016). The evolutionary emergence of what we call "emotions". Cognition and Emotion, 30, 609-620. https://doi. org/10.1080/02699931.2016.1145106

Friston, K. J. (2005). A theory of cortical responses. Philosophical Transactions of the Royal Society, B: Biological Sciences, 360, 815-836. https://doi.org/10.1098/rstb.2005.1622

Funder, D. C. (1991). Global traits: A neo-allportian approach to personality. Psychological Science, 2, 31-39. https://doi.org/ 10.1111/j.1467-9280.1991.tb00093.x 
Gable, P. A., \& Harmon-Jones, E. (2008). Approach-motivated positive affect reduces breadth of attention. Psychological Science, 19, 476-482. https://doi.org/10.1111/j.1467-9280.2008.02112.x

Geukes, K., Nestler, S., Hutteman, R., Küfner, A. C. P., \& Back, M. D. (2017). Trait personality and state variability: Predicting individual differences in within-and cross-context fluctuations in affect, self-evaluations, and behavior in everyday life. Journal of Research in Personality, 69, 124-138. https://doi.org/10.1016/j. jrp.2016.06.003

Gollwitzer, P. M. (2012). Mindset theory of action phases. In P. A. van Lange (Ed.), Handbook of theories of social psychology (pp. 526-545). Los Angeles, CA, USA: Sage. https://doi.org/ 10.4135/9781446249215.n26.

Goschke, T., \& Kuhl, J. (1993). Representation of intentions: Persisting activation in memory. Journal of Experimental Psychology: Learning, Memory, and Cognition, 19, 1211-1226.

Gray, J. A., \& McNaughton, N. (2000). Fundamentals of the septo-hippocampal system. In The neuropsychology of anxiety: An enquiry into the functions of septo-hippocampal system (2nd ed., pp. 204-232). Oxford, UK: Oxford University press.

Griffith, J. W., Zinbarg, R. E., Craske, M. G., Mineka, S., Rose, R. D., Waters, A. M., \& Sutton, J. M. (2010). Neuroticism as a common dimension in the internalizing disorders. Psychological Medicine, 40, 1125-1136. https://doi.org/10.1017/ S0033291709991449

Gross, J. J. (2014). Emotion regulation: Conceptual and empirical foundations. In J. J. Gross (Ed.), Handbook of emotion regulation (pp. 3-22), 2. New York, NY, USA: Guilford Press.

Gross, J. J., \& Feldman-Barrett, L. (2011). Emotion generation and emotion regulation: One or two depends on your point of view. Emotion Review, 3, 8-16. https://doi.org/10.1177/ 1754073910380974

Gross, J. J., \& John, O. P. (2003). Individual differences in two emotion regulation processes: Implications for affect, relationships, and well-being. Journal of Personality and Social Psychology, 85, 348-362. https://doi.org/10.1037/00223514.85.2.348

Hebb, D. O. (1949). The organization of behavior. New York, NY, USA: Wiley.

Heckhausen, H., \& Gollwitzer, P. M. (1987). Thought contents and cognitive functioning in motivational versus volitional states of mind. Motivation and Emotion, 11, 101-120. https://doi.org/ 10.1007/BF00992338

Heine, S. J., Proulx, T., \& Vohs, K. D. (2006). The meaning maintenance model: On the coherence of social motivations. Personality and Social Psychology Review, 10, 88-110. https://doi.org/ 10.1207/s15327957pspr1002_1

Higgins, E. T. (1997). Beyond pleasure and pain. American Psychologist, 52, 1280-1300. https://doi.org/10.1037/0003066X.52.12.1280

Hirsh, J. B., \& Inzlicht, M. (2008). The devil you know: Neuroticism predicts neural response to uncertainty. Psychological Science, 19, 962-967. https://doi.org/10.1111/j.14679280.2008.02183.x

Hsieh, S., Yu, Y. T., Chen, E. H., Yang, C. T., \& Wang, C. H. (2020). ERP correlates of a flanker task with varying levels of analytic-holistic cognitive style. Personality and Individual Differences, 153, $109673 . \quad \mathrm{https}$ ://doi.org/10.1016/j. paid.2019.109673

Hull, C. L. (1943). Principles of behavior. New York, NY, USA: Appleton-Century-Crofts.

Hunt, K. J., Sbarbaro, D., Żbikowski, R., \& Gawthrop, P. J. (1992). Neural networks for control systems - a survey. Automatica, 28, 1083-1112. https://doi.org/10.1016/0005-1098(92)90053-I

Jonas, E., McGregor, I., Klackl, J., Agroskin, D., Fritsche, I., Holbrook, C., Nash, K., ... Quirin, M. (2014). Threat and defense: From anxiety to approach. In J. M. Olson, \& M. P. Zanna (Eds.), Advances in experimental social psychology (49th ed., pp. 219-286). San Diego, CA, USA: Academic Press.
Kahneman, D. (2003). A perspective on judgment and choice: Mapping bounded rationality. American Psychologist, 58, 697-720. https://doi.org/10.1037/0003-066X.58.9.697

Kaufman, S. B. (2013). Opening up openness to experience: A four-factor model and relations to creative achievement in the arts and sciences. The Journal of Creative Behavior, 47, 233-255. https://doi.org/10.1002/jocb.33

Kaufman, S. B., DeYoung, C. G., Gray, J. R., Jiménez, L., Brown, J., \& Mackintosh, N. (2010). Implicit learning as an ability. Cognition, $\quad 116, \quad 321-340 . \quad$ https://doi.org/10.1016/j. cognition.2010.05.011

Kazén, M., Kuhl, J., \& Quirin, M. (2015). Personality interacts with implicit affect to predict performance in analytic versus holistic processing. Journal of Personality, 83, 251-261. https://doi.org/ 10.1111/jopy. 12100

Kazén, M., \& Quirin, M. (2017). The integration of motivation and volition in personality-systems interactions theory. In S. L. Koole, M. Kazén, M. Quirin, \& N. Baumann (Eds.), Why people do the things they do: Building on Julius Kuhl's contributions to the psychology of motivation and volition (pp. 15-30). Goettingen, Germany: Hogrefe.

Keller, H., Chasiotis, A., \& Runde, B. (1992). Intuitive parenting programs in German, American, and Greek parents of 3-monthold infants. Journal of Cross-Cultural Psychology, 23, 510-520. https://doi.org/10.1177/0022022192234007

Kochanska, G., Aksan, N., Penney, S. J., \& Doobay, A. F. (2007). Early positive emotionality as a heterogenous trait: Implications for children's self-regulation. Journal of Personality and Social Psychology, 93, 1054-1066.

Koole, S. L. (2009). The psychology of emotion regulation: An integrative review. Cognition and Emotion, 23, 4-41. https://doi. org $/ 10.1080 / 02699930802619031$

Koole, S. L., \& Jostmann, N. B. (2004). Getting a grip on your feelings: Effects of action orientation and external demands on intuitive affect regulation. Journal of Personality and Social Psychology, 87, 974-990.

Krienen, F. M., Yeo, B. T. T., \& Buckner, R. L. (2014). Reconfigurable task-dependent functional coupling modes cluster around a core functional architecture. Philosophical Transactions of the Royal Society, B: Biological Sciences, 369, 20130526. https://doi.org/10.1098/rstb.2013.0526

Kuhl, J. (1981). Motivational and functional helplessness: The moderating effect of state versus action orientation. Journal of Personality and Social Psychology, 40, 155-170. https://doi.org/ 10.1037/0022-3514.40.1.155

Kuhl, J. (1984). Volitional aspects of achievement motivation and learned helplessness: Toward a comprehensive theory of actioncontrol. In B. A. Maher (Ed.), Progress in experimental personality research (pp. 99-171), 13. New York, NY, USA: Academic Press.

Kuhl, J. (1994). A theory of action and state orientations. In J. Kuhl, \& J. Beckmann (Eds.), Volition and personality: State versus action orientation (pp. 9-46). Goettingen, Germany: Hogrefe \& Huber.

Kuhl, J. (2000a). A functional-design approach to motivation and self-regulation: The dynamics of personality systems and interactions. In M. Boekaerts, \& P. R. Pintrich (Eds.), Handbook of self-regulation (pp. 111-169). San Diego, CA, USA: Academic Press. https://doi.org/10.1016/B978-012109890-2/ 50034-2.

Kuhl, J. (2000b). The volitional basis of personality systems interaction theory: Applications in learning and treatment contexts. International Journal of Educational Research, 33, 665-703. https://doi.org/10.1016/S0883-0355(00)00045-8

Kuhl, J., \& Atkinson, J. W. (1986). Motivation, thought, and action. New York, NY, USA: Praeger.

Kuhl, J., \& Fuhrmann, A. (1998). Decomposing self-regulation and self-control: The volitional components inventory. In J. Heckhausen, \& C. S. Dweck (Eds.), Motivation and self-regulation across the life span (pp. 15-49). Cambridge, 
UK: Cambridge University Press. https://doi.org/10.1017/ CBO9780511527869.003.

Kuhl, J., \& Kazén, M. (2008). Motivation, affect, and hemispheric asymmetry: Power versus affiliation. Journal of Personality and Social Psychology, 95, 456-469. https://doi.org/10.1037/00223514.95.2.456

Kuhl, J., Koole, S. L., \& Quirin, M. (2015). Being someone: The integrated self as a neuropsychological system. Social and Personality Psychology Compass, 9, 115-132.

Kuhl, J., Mitina, O., \& Koole, S. L. (2017). The extended trust hypothesis: Single-attractor self-contagion in day-to-day changes in implicit positive affect predicts action-oriented coping and psychological symptoms. Nonlinear Dynamics, Psychology, and Life Sciences, 21, 505-518.

Kuhl, J., Quirin, M., \& Koole, S. L. (2020). The functional architecture of human motivation: Personality systems interactions theory. In A. J. Elliot (Ed.), Advances in motivation science 7. Cambridge, UK: Elsevier.

Lahey, B. B. (2009). Public health significance of neuroticism. American Psychologist, 64, 241-256. https://doi.org/10.1037/ a0015309

Lee, J. J. (2012). Correlation and causation in the study of personality. European Journal of Personality, 26, 372-390. https://doi. org/10.1002/per.1863

Lehéricy, S., Bardinet, E., Tremblay, L., Van de Moortele, P.-F., Pochon, J.-B., Dormont, D., Kim, D.-S., ... Ugurbil, K. (2006). Motor control in basal ganglia circuits using fMRI and brain atlas approaches. Cerebral Cortex, 16, 149-161. https://doi.org/ $10.1093 /$ cercor/bhi089

Lewin, K. (1935). A dynamic theory of personality: Selected papers. New York, NY, USA: McGraw-Hill.

Lieberman, M. D. (2003). Reflexive and reflective judgment processes: A social cognitive neuroscience approach. In J. P. Forgas, K. D. Williams, \& W. von Hippel (Eds.), Social judgments: Implicit and explicit processes (pp. 44-67). New York, NY, USA: Cambridge University Press.

Lindquist, K. A., Satpute, A. B., Wager, T. D., Weber, J., \& Barrett, L. F. (2015). The brain basis of positive and negative affect: Evidence from a meta-analysis of the human neuroimaging literature. Cerebral Cortex, 26, 1910-1922.

Luhmann, N. (1992). Die Wissenschaft der Gesellschaft [the art of society]. Frankfurt am Main, Germany: Suhrkamp.

Lukaszewski, A. W. (2013). Testing an adaptationist theory of trait covariation: Relative bargaining power as a common calibrator of an interpersonal syndrome. European Journal of Personality, 27, 328-345. https://doi.org/10.1002/per.1908

March, J. G. (1991). Exploration and exploitation in organizational learning. Organization Science, 2, 71-87. https://doi.org/ 10.1287/orsc.2.1.71

Marusak, H. A., Thomason, M. E., Peters, C., Zundel, C., Elrahal, F., \& Rabinak, C. A. (2016). You say 'prefrontal cortex' and I say 'anterior cingulate': Meta-analysis of spatial overlap in amygdala-to-prefrontal connectivity and internalizing symptomology. Translational Psychiatry, 6, e944. https://doi. org/10.1038/tp.2016.218

Mason, S. J. (1953). Feedback theory-Some properties of signal flow graphs. Proceedings of the IRE, 41, 1144-1156. https:// doi.org/10.1109/JRPROC.1953.274449

Mayer, J. D. (2015). The personality systems framework: Current theory and development. Journal of Research in Personality, 56, 4-14. https://doi.org/10.1016/j.jrp.2015.01.001

Mayer, J. D., Salovey, P., \& Caruso, D. R. (2008). Emotional intelligence: New ability or eclectic traits? American Psychologist, 63, 503-517. https://doi.org/10.1037/0003-066X.63.6.503

McAdams, D. P., \& Pals, J. L. (2006). A new Big Five: Fundamental principles for an integrative science of personality. American Psychologist, 61, 204-217. https://doi.org/10.1037/0003066X.61.3.204
McClelland, D. C. (1985). How motives, skills, and values determine what people do. American Psychologist, 40, 812-825. https://doi.org/10.1037/0003-066X.40.7.812

Miller, J. G., Xia, G., \& Hastings, P. D. (2019). Resting heart rate variability is negatively associated with mirror neuron and limbic response to emotional faces. Biological Psychology, 146, 107717. https://doi.org/10.1016/j.biopsycho.2019.107717

Miller, N. E. (1944). Experimental studies of conflict. In J. M. Hunt (Ed.), Personality and the behavior disorders (pp. 431-465). New York, NY, USA: Ronald Press.

Mischel, W., \& Shoda, Y. (1995). A cognitive-affective system theory of personality: Reconceptualizing situations, dispositions, dynamics, and invariance in personality structure. Psychological Review, 102, 246-268. https://doi.org/10.1037/0033295X.102.2.246

Moeller, S. K., Robinson, M. D., \& Bresin, K. (2010). Integrating trait and social-cognitive views of personality: Neuroticism, implicit stress priming, and neuroticism-outcome relationships. Personality and Social Psychology Bulletin, 36, 677-689. https:// doi.org/10.1177/0146167210367487

Morawetz, C., Bode, S., Derntl, B., \& Heekeren, H. R. (2017). The effect of strategies, goals and stimulus material on the neural mechanisms of emotion regulation: A meta-analysis of fMRI studies. Neuroscience \& Biobehavioral Reviews, 72, 111-128. https://doi.org/10.1016/j.neubiorev.2016.11.014

Mõttus, R., Condon, D., Wood, D., \& Epskamp, S. (2018). Call for papers: "New approaches toward conceptualizing and assessing personality": Joint special issue of European Journal of Psychological Assessment and European Journal of Personality. European Journal of Psychological Assessment, 34, 287-289. https://doi.org/10.1027/1015-5759/a000493

Murray, H. A. (1938). Explorations in personality. New York, NY, USA: Oxford University Press.

Nettle, D. (2006). The evolution of personality variation in humans and other animals. American Psychologist, 61, 622-631. https:// doi.org/10.1037/0003-066X.61.6.622

Ng, W., \& Diener, E. (2009). Personality differences in emotions: Does emotion regulation play a role? Journal of Individual Differences, 30, 100-106. https://doi.org/10.1027/16140001.30.2.100

Nguyen, D. H., \& Widrow, B. (1990). Neural networks for self-learning control systems. IEEE Control Systems Magazine, 10, 18-23. https://doi.org/10.1109/37.55119

Oler, J. A., Fox, A. S., Shelton, S. E., Rogers, J., Dyer, T. D., Davidson, R. J., Shelledy, W., ... Kalin, N. H. (2010). Amygdalar and hippocampal substrates of anxious temperament differ in their heritability. Nature, 466, 864-868.

Olvet, D. M., \& Hajcak, G. (2008). The error-related negativity (ERN) and psychopathology: Toward an endophenotype. Clinical Psychology Review, 28, 1343-1354. https://doi.org/10.1016/ j.cpr.2008.07.003

O’Reilly, R. C., Munakata, Y., Frank, M. J., Hazy, T. E., \& Contributors (2012). Computational cognitive neuroscience Wiki book, 1st Edition. Available from: http://ccnbook.colorado.edu

Paulhus, D. L., Lysy, D. C., \& Yik, M. S. M. (1998). Self-report measures of intelligence: Are they useful as proxy IQ tests? Journal of Personality, 66, 525-554.

Pearl, J. (2009). Causality: Models, reasoning, and inference (2nd ed.). New York, NY, USA: Cambridge University Press. https:// doi.org/10.1017/CBO9780511803161.

Pickering, A. D., \& Pesola, F. (2014). Modeling dopaminergic and other processes involved in learning from reward prediction error: Contributions from an individual differences perspective. Frontiers in Human Neuroscience, 8, 740. https://doi.org/ 10.3389/fnhum.2014.00740

Poldrack, R. A. (2011). Inferring mental states from neuroimaging data: From reverse inference to large-scale decoding. Neuron, 72, 692-697. https://doi.org/10.1016/j.neuron.2011.11.001 
Pool, E., Brosch, T., Delplanque, S., \& Sander, D. (2016). Attentional bias for positive emotional stimuli: A meta-analytic investigation. Psychological Bulletin, 142, 79-106. https://doi.org/ 10.1037/bul0000026

Powers, W. T. (1973). Behavior: The control of perception. Chicago, IL, USA: Aldine.

Powers, W. T. (1978). Quantitative analysis of purposive systems: Some spadework at the foundations of scientific psychology. Psychological Review, 85, 417-435. https://doi.org/10.1037/0033295X.85.5.417

Pytlik Zillig, L. M., Hemenover, S. H., \& Dienstbier, R. A. (2002). What do we assess when we assess a Big 5 trait? A content analysis of the affective, behavioral, and cognitive processes represented in Big 5 personality inventories. Personality and Social Psychology Bulletin, 28, 847-858. https://doi.org/10.1177/ 0146167202289013

Quirin, M., Düsing, R., \& Kuhl, J. (2013). Implicit affiliation motive predicts correct intuitive judgment. Journal of Individual Differences, 34, 24-31. https://doi.org/10.1027/1614-0001/ a000086

Quirin, M., Kazén, M., \& Kuhl, J. (2009). When nonsense sounds happy or helpless: The Implicit Positive and Negative Affect Test (IPANAT). Journal of Personality and Social Psychology, 97, 500-516. https://doi.org/10.1037/a0016063

Quirin, M., \& Kuhl, J. (2018). The Self-Access Form (SAF): Development and validation in the context of personality functioning and health. Journal of Individual Differences, 39, 1-17. https:// doi.org/10.1027/1614-0001/a000244

Quirin, M., Kuhl, J., \& Düsing, R. (2011). Oxytocin buffers cortisol responses to stress in individuals with impaired emotion regulation abilities. Psychoneuroendocrinology, 36, 898-904. https:// doi.org/10.1016/j.psyneuen.2010.12.005

Quirin, M., \& Lane, R. D. (2012). The construction of emotional experience requires the integration of implicit and explicit emotional processes. Behavioral and Brain Sciences, 35, 159-160. https://doi.org/10.1017/S0140525X11001737

Quirin, M., Tops, M., \& Kuhl, J. (2019). Autonomous motivation, internalization, and the integrative self: A self-regulation framework of interacting neuropsychological systems. In R. M. Ryan (Ed.), The Oxford handbook of human motivation (pp. 393-413). New York, NY, USA: Oxford University Press.

Radtke, E. L., Düsing, R., Kuhl, J., Tops, M., \& Quirin, M. (2020). Personality, stress, and intuition: Emotion regulation abilities moderate the effect of stress-dependent cortisol increase on coherence judgments. Frontiers in Psychology, 11, 339. https:// doi.org/10.3389/fpsyg.2020.00339

Rao, R. P. N., \& Ballard, D. H. (1999). Predictive coding in the visual cortex: A functional interpretation of some extra-classical receptive-field effects. Nature Neuroscience, 2, 79-87. https:// doi.org/10.1038/4580

Rasmussen, A. S., \& Berntsen, D. (2010). Personality traits and autobiographical memory: Openness is positively related to the experience and usage of recollections. Memory, 18, 774-786. https://doi.org/10.1080/09658211.2010.514270

Rasmussen, H. N., Wrosch, C., Scheier, M. F., \& Carver, C. S. (2006). Self-regulation processes and health: The importance of optimism and goal adjustment. Journal of Personality, 74, 1721-1748. https://doi.org/10.1111/j.1467-6494.2006.00426.x

Rauthmann, J. F. (2015). Persönlichkeit als informationsprozessierendes System: Ein systemisch-synergetischer Zugang. Psychology of Everyday Activity, 8, 36-64.

Rauthmann, J. F. (2016). Motivational factors in the perception of psychological situation characteristics. Social and Personality Psychology Compass, 10, 92-108. https://doi.org/10.1111/ spc3.12239

Rauthmann, J. F. (Ed) (2020). The handbook of personality dynam$i$ ics and processes. Amsterdam, The Netherlands: Elsevier.
Rauthmann, J. F., Gallardo-Pujol, D., Guillaume, E. M., Todd, E., Nave, C. S., Sherman, R. A., Ziegler, M., ... Funder, D. C. (2014). The Situational Eight DIAMONDS: A taxonomy of major dimensions of situation characteristics. Journal of Personality and Social Psychology, 107, 677-718. https://doi.org/10.1037/ a0037250

Rauthmann, J. F., \& Sherman, R. A. (2016). Situation change: Stability and change of situation variables between and within persons. Frontiers in Psychology, 6. https://doi.org/10.3389/ fpsyg.2015.01938

Read, S. J., Brown, A. D., Wang, P., \& Miller, L. C. (2018). The virtual personalities neural network model: Neurobiological underpinnings. Personality Neuroscience., 1, e10. https://doi.org/ 10.1017/pen.2018.6

Read, S. J., Droutman, V., \& Miller, L. C. (2017). Virtual personalities: A neural network model of the structure and dynamics of personality. In R. R. Vallacher, S. J. Read, \& A. Nowak (Eds.), Computational social psychology (1st ed., pp. 15-37). New York, NY, USA: Routledge.

Read, S. J., Monroe, B. M., Brownstein, A. L., Yang, Y., Chopra, G., \& Miller, L. C. (2010). A neural network model of the structure and dynamics of human personality. Psychological Review, $117,61-92$

Read, S. J., Smith, B. J., Droutman, V., \& Miller, L. C. (2017). Virtual personalities: Using computational modeling to understand within-person variability. Journal of Research in Personality, 69, 237-249.

Revelle, W., \& Condon, D. M. (2015). A model for personality at three levels. Journal of Research in Personality, 56, 70-81. https://doi.org/10.1016/j.jrp.2014.12.006

Revelle, W., Humphreys, M. S., Simon, L., \& Gilliland, K. (1980). The interactive effect of personality, time of day, and caffeine: A test of the arousal model. Journal of Experimental Psychology: General, 109, 1-31.

Robinson, M. D., \& Gordon, K. H. (2011). Personality dynamics: Insights from the personality social cognitive literature. Journal of Personality Assessment, 93, 161-176. https://doi.org/ 10.1080/00223891.2010.542534

Robinson, M. D., Klein, R. J., \& Persich, M. R. (2019). Personality traits in action: A cognitive behavioral version of the social cognitive paradigm. Personality and Individual Differences, 147, 214-222. https://doi.org/10.1016/j.paid.2019.04.041

Robinson, M. D., \& Wilkowski, B. M. (2015). Personality processes and processes as personality: A cognitive perspective In M. Mikulincer, P. R. Shaver, M. L. Cooper, \& R. J. Larsen (Eds.), APA handbook of personality and social psychology. Personality processes and individual differences (pp. 129-145), 4. Washington, D. C., USA: American Psychological Association.

Rosenberg, N., Rufer, M., Lichev, V., Ihme, K., Grabe, H.-J., Kugel, H., Kersting, A., et al. (2016). Observer-rated alexithymia and its relationship with the five-factor-model of personality. Psychologica Belgica, 56, 118-134. https://doi.org/10.5334/ pb.302

Rueter, A. R., Abram, S. V., MacDonald, A. W., Rustichini, A., \& DeYoung, C. G. (2018). The goal priority network as a neural substrate of conscientiousness. Human Brain Mapping, 39, 3574-3585. https://doi.org/10.1002/hbm.24195

Rumelhart, D. E., McClelland, J. L., \& PDP Research Group (Eds) (1986). Parallel distributed processing: Explorations in the microstructure of cognition 1. Cambridge, MA, USA: MIT press.

Rusting, C. L., \& Larsen, R. J. (1997). Extraversion, neuroticism, and susceptibility to positive and negative affect: A test of two theoretical models. Personality and Individual Differences, 22, 607-612. https://doi.org/10.1016/S0191-8869 (96)00246-2

Salovey, P., \& Grewal, D. (2005). The science of emotional intelligence. Current Directions in Psychological Science, 14, 281-285. https://doi.org/10.1111/j.0963-7214.2005.00381.x 
Schlüter, C., Fraenz, C., Pinnow, M., Voelkle, M. C., Güntürkün, O., \& Genç, E. (2018). Volition and academic achievement: Interindividual differences in action control mediate the effects of conscientiousness and sex on secondary school grading. Motivation Science, 4, 262-273. https://doi.org/10.1037/ mot0000083

Schneider, M. E. (2015). Motivational development, systems theory of. In J. D. Wright (Ed.), International encyclopedia of the social \& behavioral sciences (2nd ed., pp. 10120-10125), 2. New York, NY, USA: Elsevier. https://doi.org/10.1016/B978-0-08-0970868.23027-4.

Schneirla, T. C. (1959). An evolutionary and developmental theory of biphasic processes underlying approach and withdrawal. In M. R. Jones (Ed.), Nebraska symposium on motivation (pp. 1-42). Lincoln, NE, USA: University of Nebraska Press.

Schultz, W. (2013). Updating dopamine reward signals. Current Opinion in Neurobiology, 23, 229-238. https://doi.org/10.1016/ j.conb.2012.11.012

Serfass, D. G., \& Sherman, R. A. (2015). Situations in 140 characters: Assessing real-world situations on twitter. PLOS ONE, 10, e0143051. https://doi.org/10.1371/journal.pone.0143051

Servaas, M. N., Van Der Velde, J., Costafreda, S. G., Horton, P., Ormel, J., Riese, H., \& Aleman, A. (2013). Neuroticism and the brain: A quantitative meta-analysis of neuroimaging studies investigating emotion processing. Neuroscience \& Biobehavioral Reviews, 37, 1518-1529. https://doi.org/10.1016/j. neubiorev.2013.05.005

Shackman, A. J., Tromp, D. P. M., Stockbridge, M. D., Kaplan, C. M., Tillman, R. M., \& Fox, A. S. (2016). Dispositional negativity: An integrative psychological and neurobiological perspective. Psychological Bulletin, 142, 1275-1314. https://doi.org/ 10.1037/bul0000073

Shah, J. Y., Friedman, R., \& Kruglanski, A. W. (2002). Forgetting all else: On the antecedents and consequences of goal shielding. Journal of Personality and Social Psychology, 83, 1261-1280.

Sherman, R. A., Rauthmann, J. F., Brown, N. A., Serfass, D. G., \& Jones, A. B. (2015). The independent effects of personality and situations on real-time expressions of behavior and emotion. Journal of Personality and Social Psychology, 109, 872-888. https://doi.org/10.1037/pspp0000036

Shoda, Y., Wilson, N. L., Chen, J., Gilmore, A. K., \& Smith, R. E. (2013). Cognitive-affective processing system analysis of intra-individual dynamics in collaborative therapeutic assessment: Translating basic theory and research into clinical applications. Journal of Personality, 81, 554-568. https://doi.org/ 10.1111/jopy. 12015

Silverman, M. H., Wilson, S., Ramsay, I. S., Hunt, R. H., Thomas, K. M., Krueger, R. F., \& Iacono, W. G. (2019). Trait neuroticism and emotion neurocircuitry: Functional magnetic resonance imaging evidence for a failure in emotion regulation. Development and Psychopathology, 31, 1085-1099.

Smillie, L. D. (2013). Extraversion and reward processing. Current Directions in Psychological Science, 22, 167-172. https://doi. org/10.1177/0963721412470133

Smillie, L. D., Hayley, K. J., Hughes, D. M., Wacker, J., Cooper, A. J., \& Pickering, A. D. (2019). Extraversion and rewardprocessing: Consolidating evidence from an electroencephalographic index of reward-prediction-error. Biological Psychology, 146, 107735. https://doi.org/10.1016/j.biopsycho.2019.107735

Smillie, L. D., Varsavsky, V., Avery, R. E., \& Perry, R. (2016). Trait intellect predicts cognitive engagement: Evidence from a resource allocation perspective. European Journal of Personality, 30, 215-226. https://doi.org/10.1002/per.2059

Sosnowska, J., Kuppens, P., De Fruyt, F., \& Hofmans, J. (2019). A dynamic systems approach to personality: The personality dynamics (PersDyn) model. Personality and Individual Differences, $144,11-18$

Southward, M. W., Altenburger, E. M., Moss, S. A., Cregg, D. R., \& Cheavens, J. S. (2018). Flexible, yet firm: A model of healthy emotion regulation. Journal of Social and Clinical Psychology, 37, 231-251. https://doi.org/10.1521/jscp.2018.37.4.231

Specht, J., Bleidorn, W., Denissen, J. J., Hennecke, M., Hutteman, R., Kandler, C., \& Zimmermann, J. (2014). What drives adult personality development? A comparison of theoretical perspectives and empirical evidence. European Journal of Personality, 28, 216-230. https://doi.org/10.1002/per.1966

Spirtes, P., Glymour, C. N., \& Scheines, R. (2000). Causation, prediction, and search. Cambridge, MA, USA: MIT Press.

Stahl, J., \& Rammsayer, T. (2008). Extroversion-related differences in speed of premotor and motor processing as revealed by lateralized readiness potentials. Journal of Motor Behavior, 40, 143-154. https://doi.org/10.3200/JMBR.40.2.143-154

Strack, F., \& Deutsch, R. (2004). Reflective and impulsive determinants of social behavior. Personality and Social Psychology Review, 8, 220-247.

Suslow, T., Ihme, K., Quirin, M., Lichev, V., Rosenberg, N., Bauer, J., Bomberg, L., ... Lobsien, D. (2015). Implicit affectivity and rapid processing of affective body language: An fMRI study. Scandinavian Journal of Psychology, 56, 545-552. https://doi. org/10.1111/sjop. 12227

Takeshima, Y., \& Gyoba, J. (2014). Hemispheric asymmetry in the auditory facilitation effect in dual-stream rapid serial visual presentation tasks. PLOS ONE, 9, e104131. https://doi.org/10.1371/ journal.pone.0104131

Tamir, M. (2016). Why do people regulate their emotions? A taxonomy of motives in emotion regulation. Personality and Social Psychology Review, 20, 199-222. https://doi.org/10.1177/ 1088868315586325

Tellegen, A. (1981). Practicing the two disciplines for relaxation and enlightenment: Comment on "Role of the feedback signal in electromyograph biofeedback: The relevance of attention" by Qualls and Sheehan. Journal of Experimental Psychology: General, 110, 217-226. https://doi.org/10.1037/00963445.110.2.217

Tellegen, A. (1982). Brief manual for the multidimensional personality questionnaire. Unpublished manuscript, University of Minnesota, Minneapolis, MN, USA.

Tellegen, A., \& Atkinson, G. (1974). Openness to absorbing and self-altering experiences ("absorption"), a trait related to hypnotic susceptibility. Journal of Abnormal Psychology, 83, 268-277. https://doi.org/10.1037/h0036681

Tops, M., Boksem, M. A. S., Luu, P., \& Tucker, D. M. (2010). Brain substrates of behavioral programs associated with self-regulation. Frontiers in Cognition, 1, 1-14.

Tops, M., IJzerman, H., \& Quirin, M. (2020). Personality dynamics in the brain: Individual differences in updating of representations and their phylogenetic roots. To appear. In J. Rauthmann (Ed.), The handbook of personality dynamics and processes. Amsterdam, the Netherlands: Elsevier.

Tops, M., Montero-Marín, J., \& Quirin, M. (2016). Too much of a good thing: A neuro-dynamic personality model explaining engagement and its protective inhibition. In S.-I. Kim, J. Reeve, \& M. Bong (Eds.), Recent developments in neuroscience research on human motivation (pp. 283-319). Bingley, UK: Emerald Group Publishing Limited. https://doi.org/10.1108/S0749742320160000019012.

Tops, M., Quirin, M., Boksem, M. A. S., \& Koole, S. L. (2017). Large-scale neural networks and the lateralization of motivation and emotion. International Journal of Psychophysiology, 119, 41-49. https://doi.org/10.1016/j.ijpsycho.2017.02.004

Uddin, L. Q., Yeo, B. T. T., \& Spreng, R. N. (2019). Towards a universal taxonomy of macro-scale functional human brain networks. Brain Topography, 32, 926-942. https://doi.org/10.1007/ s10548-019-00744-6

Ungerleider, L. G., \& Mishkin, M. (1982). Two cortical visual systems. In D. J. Ingle, M. A. Goodale, \& R. J. W. Mansfield (Eds.), Analysis of visual behavior (pp. 549-586). Cambridge, MA, USA: MIT Press. 


\section{Quirin et al.}

Vallacher, R. R., Read, S. J., \& Nowak, A. (2002). The dynamical perspective in personality and social psychology. Personality and Social Psychology Review, 6, 264-273. https://doi.org/ 10.1207/S15327957PSPR0604_01

Van Egeren, L. F. (2009). A cybernetic model of global personality traits. Personality and Social Psychology Review, 13, 92-108. https://doi.org/10.1177/1088868309334860

Wacker, J., \& Smillie, L. D. (2015). Trait extraversion and dopamine function. Social and Personality Psychology Compass, 9, 225-238. https://doi.org/10.1111/spc3.12175

Watson, D. (2000). Mood and temperament. New York, NY, USA: Guilford Press.

Weinberg, A., Kotov, R., \& Proudfit, G. H. (2015). Neural indicators of error processing in generalized anxiety disorder, obsessive-compulsive disorder, and major depressive disorder. Journal of Abnormal Psychology, 124, 172-185. https://doi.org/ 10.1037/abn0000019

Whitmer, A. J., \& Gotlib, I. H. (2013). An attentional scope model of rumination. Psychological Bulletin, 139, 1036-1061.

Wiener, N. (1948). Cybernetics. Scientific American, 159, 14-19.

Wilson, T. D., \& Dunn, E. W. (2004). Self-knowledge: Its limits, value, and potential for improvement. Annual Review of
Psychology, 55, 493-518. https://doi.org/10.1146/annurev. psych.55.090902.141954

Wilt, J., \& Revelle, W. (2009). Extraversion. In M. Leary, \& R. Hoyle (Eds.), Handbook of individual differences in social behavior (pp. 27-45). New York, NY, USA: Guilford Press.

Wood, D., Gardner, M. H., \& Harms, P. D. (2015). How functionalist and process approaches to behavior can explain trait covariation. Psychological Review, 122, 84-111. https://doi.org/ 10.1037/a0038423

Yarkoni, T. (2015). Neurobiological substrates of personality: A critical overview. In M. Mikulincer, P. R. Shaver, M. L. Cooper, \& R. J. Larsen (Eds.), APA handbook of personality and social psychology. Personality processes and individual differences (pp. 61-84), 4. Washington, D. C., USA: American Psychological Association.

Yovel, I., Revelle, W., \& Mineka, S. (2005). Who sees trees before forest? The obsessive-compulsive style of visual attention. Psychological Science, 16, 123-129. https://doi.org/10.1111/ j.0956-7976.2005.00792.x 